\title{
Economic Assessment and Business Models of Rooftop Photovoltaic Systems in Multiapartment Buildings: Case Studies for Austria and Germany
}

\author{
Bernadette Fina (iD), Andreas Fleischhacker, Hans Auer, and Georg Lettner \\ Vienna University of Technology, Energy Economics Group (EEG), Gusshausstrasse 25-29/E370-3, 1040 Vienna, Austria \\ Correspondence should be addressed to Bernadette Fina; fina@eeg.tuwien.ac.at
}

Received 12 November 2017; Accepted 23 January 2018; Published 20 February 2018

Academic Editor: Onder Ozgener

Copyright (C) 2018 Bernadette Fina et al. This is an open access article distributed under the Creative Commons Attribution License, which permits unrestricted use, distribution, and reproduction in any medium, provided the original work is properly cited.

\begin{abstract}
This paper analyses the profitability and business models of shared, nonsubsidized PV systems' usage in multiapartment buildings in Austria in the context of legislative amendments which came into force in July 2017. In addition, it compares the Austrian results with those of Germany, where significantly higher retail electricity prices determine the profitability benchmark. To that end, a multiobjective optimization model is developed for the optimal dimensioning of PV systems and energy storage facilities in keeping with different end user objectives, ranging from minimizing annual electricity costs to maximizing self-consumption. The results show that the profitability of shared use of nonsubsidized PV systems is marginal in Austria. This means that, based on individual apartment load profiles, the profitability gap ranges between 0 and 40 euros per apartment, whereas the consideration of the building as total load leads to a small cost-saving potential of about 90 euros for the whole building in the best case and thus profitability. In contrast, significant profitability of shared PV systems in multiapartment buildings can be achieved in Germany, where the renewable energy surcharge results in high retail electricity prices. At present, different business models, accounting and billing concepts, are being tested in these countries to learn about the best-practice concepts.
\end{abstract}

\section{Introduction}

The profitability of photovoltaic (PV) system installations has increased considerably in recent years. In the last two decades, Germany has been a pioneer, both globally and in Europe, in terms of installed PV capacities, not least triggered by substantial financial support aimed at promoting this technology through diverse government subsidy schemes. Also other countries with already high penetration of PV generation in their electricity systems are worth mentioning as some kind of forerunners, for example, the U.S., China, Japan, Italy, and Spain. Whereas in the early phase of PV penetration, the business model was to feed subsidized (small and large scale) PV generation into the grid, this approach has been increasingly overlapped with the implementation of small rooftop PV systems in the commercial and private sector with the aim of primarily covering parts of the load and thus purchasing the residual amount of electricity from the grid only.
In the meantime, an already successfully implemented concept in Germany is the shared PV system use in multiapartment buildings. This means that owners of singlefamily houses can produce and use electricity from their own photovoltaic systems. Until recently, in Austria, selfconsumption of PV electricity was allowed for single-family homes only. With the successful amendment of legislative regulations, the implementation of shared PV systems in multiapartment buildings has been legal since July 2017.

In the context of the recent change in the Austrian electricity law [1], the aim of this paper is to examine the economic viability of supplying residents with nonsubsidized PV electricity in multiapartment buildings. Two concepts are studied: rooftop PV systems with and without energy storage. These concepts can be designed for customer objectives reached from minimizing annual electricity costs to maximizing self-consumption. In any case, the residual load can be reduced significantly through self-consumption. Annual electricity costs can also be reduced in some cases with a 
certain degree of energy self-sufficiency achieved. The empirical part of this paper elaborates an analysis of the shared PV concept's economic viability for multiapartment buildings for Austrian and German retail electricity prices. This comparison is particularly important as the variable component (per $\mathrm{kWh}$ ) of the German retail electricity price is much higher than in Austria. The reason for this is mainly the significantly higher renewable energy surcharge in Germany ("EEG-Umlage") being used to cover financial support for renewable electricity generation.

For the purpose of the mentioned analyses, an optimization model is developed in MATLAB which determines the optimal rooftop PV system's capacity for different cases, based on a fictitious multiapartment building with ten residential units. The optimal PV capacity strongly depends on the concrete optimization objectives, ranging from minimizing annual electricity costs to maximizing self-consumption. In order to enable consideration of different cases besides these two extremes, the two basic optimization objectives, minimal annual electricity costs and maximal self-consumption rate, are merged by using a multiobjective optimization approach. Thus, expectations for cost minimization as well as selfconsumption maximization can be weighted and the optimal PV capacity can be calculated accordingly. Furthermore, the annual retail electricity costs incurred and the electricity consumption from the grid is calculated to allow a comparison to the initial situation without a shared PV system installed. Finally, the model is extended by an energy storage feature. The optimal storage capacity is determined by using an extended multiobjective optimization approach. Building on this, an economic assessment of a combination of PV system and energy storage can be conducted.

The paper is organized as follows. Section 2 provides a brief overview of the latest developments and current standards in terms of the shared PV concepts. Section 3 provides a detailed mathematical description of the optimization model developed in MATLAB as well as the empirical scaling. Results of the analysis of different case studies are presented and explained in Section 4. These results are further discussed in Section 5, with a special focus on the profitability for tenants and landlords. Additionally, Section 5 provides an overview of possible business models, on the basis of the recent regulatory changes in Austria. The paper ends with the conclusions in Section 6.

\section{State of the Art}

Due to the strong efforts to increase renewable energy supply, the structure of power systems worldwide is changing from a predominantly centralized (large power plants) to a more decentralized structure with small dispersed generation units. This trend is further pushed by recent efforts of local onsite generation, including the integration of renewable energy generation in buildings, a topic being addressed in this paper. Power systems with small distributed generation units require significant efforts in management and scheduling to guarantee reliable supply. Energy concepts facilitating the integration of distributed (renewable) generation are well known in the literature as microgrids [2]. PV systems and energy storage facilities being integrated in a multiapartment building as considered in this study are, from a system perspective, not different from a microgrid, limited to the boundary of a single building.

As microgrids have been becoming increasingly important in recent years, numerous studies exist addressing several important aspects in this field. Microgrid scheduling is reviewed from various viewpoints like modeling techniques and reliability [3], energy management based on demand response [4], and generation/demand forecasting [5]. In general, the objectives of the models for the optimal design and scheduling of microgrids are cost-minimization problems under a variety of different constraints [6,7]. Owing to such research efforts, it is already possible to successfully integrate renewable energy sources in urban areas, improve the efficient use of energy in developing countries (mitigating dependency on fossil fuels and electrifying rural areas) like India $[8,9]$, or simply facilitate electrification of remote areas [10]. Generally, energy service provision in a microgrid environment can be split into the two energy services of electricity and heating/cooling. There are different studies focusing on cost-optimal sizing of local micro-CHP systems for thermal management [11] and evaluating the economic viability of micro-CHP systems in buildings [12].

Despite being mostly used in geographically narrow areas, the concept of a microgrid is also applicable for individual buildings [13]. So far, studies about microgrids in buildings do mainly focus on commercial buildings. Already in 2008, for example, an optimization approach is proposed for optimal system design for microgrids in commercial buildings [14]. More recent studies focus on introducing a heuristic operation strategy for a commercial building including a PV system and electric vehicle charging stations [15] or providing an efficient energy management for microgrids including PV prosumers based on a Stackelberg game approach [16]. Theoretically, there are no barriers for further spreading renewable energy usage in buildings, but in practice regulatory obstacles do often prevent such developments, notably in the private sector. In the U.S., for example, local distribution utilities, owning exclusive rights in a specified service territory, have prevented nationwide spreading of small-scale third-party owned and operated microgrids so far $[17,18]$, leading to ongoing discussions (e.g., currently in Maryland [19]) about bypassing such restrictions. Only 9\% of all microgrid implementations in the U.S. belong to communities (i.e., local neighborhood areas) [20]. In the private (multiapartment) building sector, there is less experience in terms of microgrid applications in the U.S.

This paper addresses the principles of microgrid generation with a single multiapartment building only. Moreover, it is limited to electricity related energy services, meaning that shared PV generation on the building's rooftop contributes to serving the individual units of the multiapartment house concerning electricity demand.

Photovoltaic electricity generation in buildings has been attracting considerable attention as a feasible solution to cover parts of the load $[21,22]$, hence offering great potential, notably in cities $[23,24]$. Recent European studies focus mainly on PV usage in office and commercial buildings [25, 
26] as well as in single-family residential buildings [27-29]. A recent German work performs a techno-economic analysis of rooftop photovoltaic self-consumption for different building types, including multifamily buildings [30]. Among the European countries, Germany puts the strongest efforts in further distributing PV usage in buildings. A novel concept called "Mieterstrommodell" enables shared use of PV systems in multiapartment buildings and has already been implemented successfully in the course of different projects [31]. Following the latest efforts to further popularize the shared PV concept in Germany, Austria has adopted corresponding legislation in July 2017 to allow shared use of PV systems in multiapartment buildings [1] too. However, the legal situation in Germany and Austria is not the same. In Germany, it is almost impossible for landlords or owner communities to install a PV system on their building's roof, as they are energy suppliers from a legal point of view. Therefore, the shared use of PV systems is often realized through contractors renting the roof of multiapartment buildings and further offering it to energy suppliers for lease, or the whole amount of PV electricity is sold to energy suppliers. They then define products of PV and grid electricity which are sold to meet the building units' demand. On the contrary, in Austria the situation is less restricted as landlords or owner communities are legally allowed to supply residents with self-generated PV electricity.

So far, studies addressing profitability of shared PV systems in multiapartment buildings, focusing on different end user objectives, still do not exist. Furthermore, as most people in cities live in rent, the tenant-landlord situation needs to be considered. This has been neglected in literature so far. This work, therefore, aims at closing this gap by evaluating the profitability of nonsubsidized shared PV systems in multiapartment buildings, while also considering the relation of tenants and landlords. Furthermore, a combination of a PV system and an energy storage facility is examined, as an energy storage enables improvements in the utilization level of PV electricity and contributes to the mitigation of supply inconsistency due to weather conditions and daytime $[32,33]$. Although the model described in Section 3 is applicable for any country, the results are calculated explicitly for Austria and compared with the situation in Germany regarding retail electricity prices. This comparison is especially interesting, due to the significant differences in the retail electricity price (high variable component in Germany due to high renewable energy surcharge), having great influence on PV systems' and storage facilities' economic viability.

\section{Methodology and Model}

A fictitious multiapartment building containing ten residential units is chosen as a basis for all analyses. These ten apartments are designated as Units 1-10 in the graphs and they are allocated real household load profiles, measured at 15-minute intervals. The ten apartments (Units 1-10) are categorized according to their annual electricity consumption. Unit 1 is assigned the load profile with the lowest annual consumption, while Unit 10 is assigned the highest one (see Figure 1).

The model assumes a PV system, oriented towards the south, at a slope angle of 30 degrees and located on the rooftop

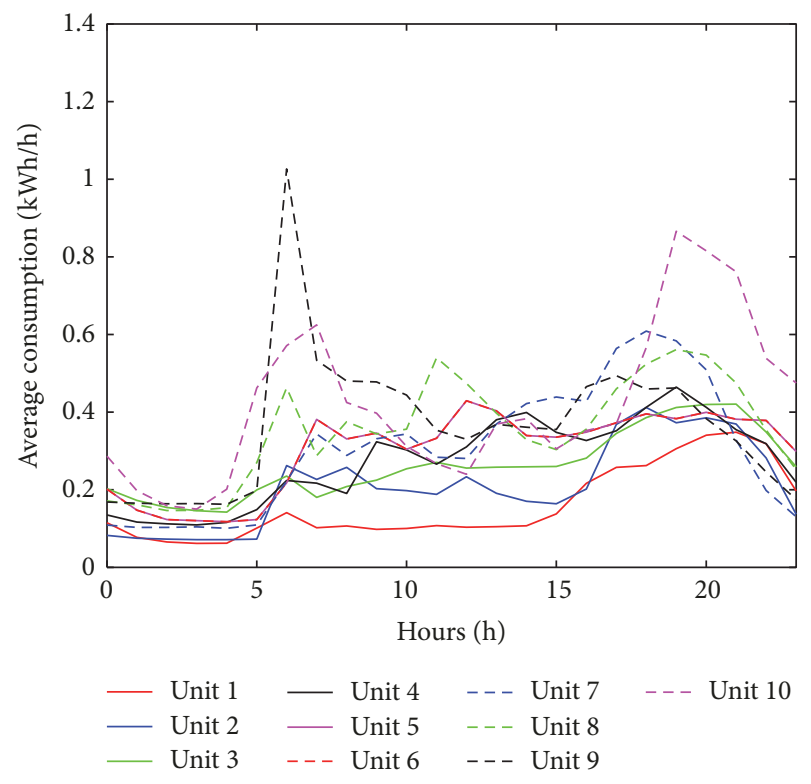

FIGURE 1: Hourly consumption average.

of a multiapartment building. The PV system size depends, on the one hand, on the residents' objectives (minimization of annual electricity costs versus maximization of the selfconsumption rate). On the other hand, the dimensioning of shared PV systems depends on whether calculations are conducted in relation to individual apartments' load profiles, or considering the whole multiapartment building as total load (sum of all load profiles of the individual apartments). The following section explains the applied multiobjective optimization approach, based on the extreme cases of minimizing annual electricity costs and maximizing the selfconsumption rate. All calculations are conducted for three different case studies:

(i) Case study 1: optimal dimensioning of the PV system for the building considered as total load (sum of load profiles of the individual apartments) (Section 3.1)

(ii) Case study 2: optimal dimensioning of the PV system for individual apartments (based on individual load profiles) (Section 3.2)

(iii) Case study 3: optimal dimensioning of the PV system and an energy storage facility for the building considered as total load (sum of load profiles of the individual apartments) (Section 4.3)

In order to carry out the optimizations in MATLAB, the toolbox Yalmip is used as an optimizer [34] and Gurobi as a solver [35]. All abbreviations used within the paper are listed in Abbreviations.

3.1. Optimal Dimensioning of a PV System for the Building Considered as Total Load. The optimization is carried out according to a total of five optimization variables: $P_{\text {peak }}$, $e_{\mathrm{pv} 2 \text { load }}, e_{\mathrm{pv} 2 \text { grid }}, e_{\text {grid }}$, and $b_{\mathrm{PV}}$. Hereby, $b_{\mathrm{PV}}$ is a binary variable that indicates if a PV system is implemented or not. $P_{\text {peak }}$ is the optimal dimension of the PV system in $\mathrm{kW}_{\text {peak }} \cdot e_{\text {pv2load }}$ 
stands for the amount of generated PV electricity used to cover the load, in $\mathrm{kWh}$, whereas $e_{\mathrm{pv} 2 \text { grid }}$ is the amount of surplus electricity generated by the PV system which is fed into the grid in $\mathrm{kWh} . e_{\text {grid }}$ designates the electricity purchased from the grid in $\mathrm{kWh}$ in order to cover the residual load. The energy flows' optimal values are resolved in 15-minute intervals.

The optimization problem is restricted by the following constraints:

(i) The load must be fully covered at any time: by PV system electricity and/or by electricity purchased from the grid.

$$
e_{\text {load }}(t)==e_{\text {pv2load }}(t)+e_{\text {grid }}(t) .
$$

(ii) The total amount of electricity generated by the PV system is either used to cover the load or fed into the grid.

$$
E(t) \cdot P_{\text {peak }}==e_{\text {pv2load }}(t)+e_{\text {pv2grid }}(t) .
$$

(iii) The PV system's installed capacity has to be greater than or equal to zero and must not exceed the maximum capacity, restricted by the available rooftop area.

$$
0 \leq P_{\text {peak }} \leq P_{\text {peak }_{\text {max }}} \cdot b_{\text {pv }} \text {. }
$$

(iv) All energy flows have to be greater than or equal to zero.

$$
\begin{aligned}
e_{\text {grid }}(t) & \geq 0, \\
e_{\text {pv2grid }}(t) & \geq 0, \\
e_{\text {pv2load }}(t) & \geq 0 .
\end{aligned}
$$

The annual electricity costs are calculated as follows:

(i) Variable (quantity-dependent) electricity costs:

$$
C_{\text {var }}(t)=c_{\text {var_elec }} \cdot e_{\text {grid }}(t)-e_{\text {pv2grid }}(t) \cdot p_{\text {feed_in }}
$$

(ii) Annuities of specific investment costs and annual fixed costs $\left(\mathcal{c}_{\text {clean }}\right.$ already transformed in the unit $\left.\mathrm{EUR} / \mathrm{kW}_{\text {peak }} / \mathrm{yr}\right)$ :

$$
C_{\text {pv_peak }}=\left(i_{0 \mathrm{pv}} \cdot \alpha_{\mathrm{pv}}+c_{\text {clean }}\right) \cdot P_{\text {peak }}
$$

(iii) Operating costs, insurance costs, and fixed costs for installation of the PV system:

$$
C_{\mathrm{pv}-b}=b_{\mathrm{pv}} \cdot\left(c_{\mathrm{op}}+c_{\mathrm{ins}}+\alpha_{\mathrm{pv}} \cdot c_{\mathrm{fix}-\mathrm{pv}}\right)
$$

(iv) Annual fixed grid connection costs for each apartment:

$$
C_{\text {other }}=c_{\text {fix_elec }}
$$

3.1.1. Minimal Cost Optimization. The objective of minimizing annual electricity costs can be written as a function to minimize the total of annual costs incurred $\left(\mathrm{EC}_{\text {min }}\right)$ :

$$
\begin{aligned}
\mathrm{EC}_{\text {min }}= & \min _{\substack{P_{\text {peak }}, e_{\text {grid }}, e_{\text {pv2load }}, e_{\text {pvegrid }}, b_{\text {pv }}}} \sum_{t=0}^{N}\left(C_{\text {var }}(t)\right)+C_{\text {pv_peak }}+C_{\text {pv_ } b} \\
& +C_{\text {other }} \cdot X,
\end{aligned}
$$

whereas $X$ is the number of apartments considered within the multiapartment building. As values are measured in 15minute intervals, $N=35040$ represents the number of time steps in one year.

3.1.2. Maximum Self-Consumption Optimization. The goal of maximizing the self-consumption rate (objective function referred to as $\mathrm{SC}_{\max }$ ) is directly related to the minimization of annual grid consumption:

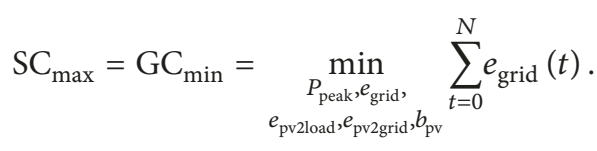

3.1.3. Multiobjective Optimization. Multiobjective optimization allows the combination of different optimization objectives by weighting them accordingly. In this case, two opposing optimization objectives, annual electricity cost minimization and self-consumption maximization, are considered and combined by using the weighting factors $\gamma$ and $(1-\gamma)$ (see (11)). They take values between zero and one, whereas their sum has to be one. Furthermore, the two original objective functions $\left(\mathrm{EC}_{\min }\right.$ and $\mathrm{SC}_{\max }$ ) have to be normalized through division by the results of the former individually conducted optimizations, described in Sections 3.1.1 and 3.1.2.

$$
\begin{aligned}
& \mathrm{MO}_{\min }=\min _{\substack{P_{\text {peak }}, e_{\text {grid }}, e_{\text {pv2load }}, e_{\text {prggrid }} b_{\mathrm{pv}}}}\left(\gamma \cdot \frac{\mathrm{EC}_{\text {min }}}{\operatorname{Result}_{\mathrm{EC}_{\text {min }}}}+(1-\gamma)\right. \\
& \left.\cdot \frac{\mathrm{SC}_{\text {max }}}{\text { Result }_{\mathrm{SC}_{\text {max }}}}\right) .
\end{aligned}
$$

3.2. Optimal Dimensioning of a PV System considering Individual Load Profiles. The overall approach, constraints, target functions, optimization variables, and the calculation formulas basically remain the same as for the building considered as total load (discussed in Section 3.1). The difference in conducting the calculations for individual load profiles is that the optimization variables change their dimension. Instead of one load profile, the individual loads of 10 apartments have to be considered separately. The vectors describing the energy flows $\left(e_{\mathrm{pv} 2 \text { grid }}, e_{\mathrm{pv} 2 \text { load }}, e_{\text {grid }}\right)$ are extended to matrices corresponding to the number of apartments. The initial scalar of the PV system capacity $\left(P_{\text {peak }}\right)$ is expanded to a vector, as 
the optimal PV system size is calculated for each apartment. The objective functions can be rewritten as

$$
\begin{gathered}
\mathrm{EC}_{\text {min }}=\min _{\substack{P_{\text {peak }}, e_{\text {grid }}, e_{\text {pv2load }}, e_{\text {pvgrid }}, b_{\text {pv }}}} \sum_{j=1}^{X}\left(\sum_{t=0}^{N}\left(C_{\text {var }}(t, j)\right)\right. \\
\left.+C_{\text {pv_peak }}(j)+C_{\text {pv_b } b}(j)+C_{\text {other }}(j)\right) \\
\mathrm{SC}_{\max }=\mathrm{GC}_{\text {min }}=\min _{\substack{P_{\text {peak }}, e_{\text {grid }}, e_{\text {pv2load }}, e_{\text {pv } 2 \text { grid }}, b_{\mathrm{pv}}}} \sum_{j=1}^{X} \sum_{t=0}^{N} e_{\text {grid }}(t, j) .
\end{gathered}
$$

$N$ represents the number of time steps for a year, whereas $X$ stands for the number of apartments considered.

The objective function of the multiobjective optimization is formulated analogously to the target function given in (11).

\subsection{Optimal Dimensioning of a PV System and an Energy} Storage Facility for the Building Considered as Total Load. When considering an energy storage facility in addition to the PV system, the optimization model and calculations given in Section 3.1 have to be adapted. Further optimization variables have to be introduced and equations have to be extended. Four additional optimization variables have to be considered besides the already existing ones: $\mathrm{SoC}, \mathrm{SoC}_{\max }, e_{\mathrm{in}}$, and $e_{\mathrm{out}}$. SoC determines the storage facility's state of charge at every time, whereas $\mathrm{SoC}_{\max }$ is the maximum storage capacity to be implemented. $e_{\text {out }}$ and $e_{\text {in }}$ represent the energy flows for discharging and charging the energy storage facility at every point in time.

The constraints also have to be extended; they can be written as follows:

(i) The load has to be covered any time by purchase of electricity from the grid, by the PV system or by the energy storage facility.

$$
e_{\text {load }}(t)==e_{\text {grid }}(t)+e_{\text {pv2load }}(t)+e_{\text {out }}(t) .
$$

(ii) Electricity generated by the PV system can be used for load coverage, for charging the energy storage facility, or it can be fed into the grid.

$$
E(t) \cdot P_{\text {peak }}==e_{\text {pv2load }}(t)+e_{\text {in }}(t)+e_{\text {pv2grid }}(t) .
$$

(iii) The storage facility's state of charge (SoC), at any point in time, is given by the former state of charge minus the electricity discharged as needed for load coverage plus the PV system's energy generation fed into the storage facility.

$$
\operatorname{SoC}(t)==\operatorname{SoC}(t-1)-\frac{e_{\text {out }}(t)}{\eta_{\text {storage }}}+e_{\text {in }}(t) \cdot \eta_{\text {storage }} \text {. }
$$

(iv) The state of charge must not exceed the maximum storage capacity.

$$
0 \leq \mathrm{SoC}(t) \leq \mathrm{SoC}_{\max } .
$$

(v) As an annual energy storage cycle is considered, it has to be empty at the beginning and the end of the year.

$$
\operatorname{SoC}(1)==\operatorname{SoC}(N)==0 \text {. }
$$

(vi) At every point in time, the energy flows for the storage facility's charging and discharging have to be greater than or equal to zero.

$$
\begin{gathered}
e_{\text {in }}(t) \geq 0, \\
e_{\text {out }}(t) \geq 0 .
\end{gathered}
$$

(vii) The constraints valid for the PV system remain the same as given in Section 3.1.

For the correct calculation of annual electricity costs, the energy storage facility's investment costs have to be taken into account. This means that the target function given in (9) has to be extended by the following cost term:

$$
C_{\text {storage }}=\alpha_{\text {storage }} \cdot i_{0_{\text {storage }}} \cdot \mathrm{SoC}_{\max } \cdot
$$

The target functions of maximizing the self-consumption rate and the multiobjective optimization given in (10) and (11) remain the same.

3.4. Empirical Scaling. The costs of electricity, of the PV system and of the storage facility, as well as operating cost assumptions, were made based on the Energy Economics Group's database [36]. Assumptions for the maximum possible PV system size as well as the maximum storage capacity were made based on the size of the fictitious multiapartment building, with an assumed surface of $160 \mathrm{~m}^{2}$ per floor. Insurance costs are calculated at $0 \mathrm{EUR} / \mathrm{yr}$, as it is assumed that the insurance premium of the PV system is included in the household or building insurance premium. All values used for the calculations are listed in Table 1.

\section{Results}

All calculations presented in this section are based on a multiobjective optimization approach (see Section 3.1.3) and depend on the weighting of the two opposing objective functions, annual electricity cost minimization and maximization of self-consumption. The sum of the two objectives' weights has to be one $(100 \%)$. An increase in the weight of one optimization objective leads to a decrease in the other one.

4.1. Separate Consideration of Apartments: Implementation of an Optimal PV System. Figures 2 and 3 show the optimally calculated PV capacity for the Austrian and German retail electricity prices. In Figure 2, no PV system is installed for the exclusive objective of minimizing annual electricity costs (weighted with 1 or $100 \%$ ) in the case of Austrian retail electricity prices. This means that residents are not able to reduce electricity costs by installing a PV system. As soon as the optimization objective changes from full costminimization (weighted with 1 or $100 \%$ ) to a multiobjective optimization (the weight of cost-minimization objective 
TABLE 1: Value assumptions.

\begin{tabular}{lcc}
\hline Abbreviation & Explanation & Value \\
\hline$P_{\text {peak_max }}$ & Maximum PV peak capacity & $21 \mathrm{~kW}$ peak \\
SoC $\max$ & Maximum state of charge & $2.5 \mathrm{EUR} / \mathrm{m}^{2} / \mathrm{yr}$ \\
$c_{\text {clean }}$ & PV system cleaning costs & $65 \mathrm{EUR} / \mathrm{yr}$ \\
$c_{\text {fix_elec }}$ for AT & Fixed costs of electricity & $50 \mathrm{EUR} / \mathrm{yr}$ \\
$c_{\text {fix_elec }}$ for DE & Fixed costs of electricity & $3372 \mathrm{EUR}$ \\
$c_{\text {fix_pv }}$ & Fixed costs when installing a PV system \\
$c_{\text {ins }}$ & Annual insurance costs of PV system & $0 \mathrm{EUR} / \mathrm{yr}$ \\
$c_{\text {op }}$ & Operational costs of PV system & $60 \mathrm{EUR} / \mathrm{yr}$ \\
$c_{\text {var_elec }}$ for AT & Variable component of retail electricity price \\
$c_{\text {var_elec }}$ for DE & Variable component of retail electricity price & $0.148 \mathrm{EUR} / \mathrm{kWh}$ \\
$i_{\text {0pv }}$ & Specific investment costs of PV system & $0.2732 \mathrm{EUR} / \mathrm{kWh}$ \\
$i_{\text {0storage }}$ & Specific investment costs of storage facility & $1029 \mathrm{EUR} / \mathrm{kW}$ \\
$p_{\text {feed_in }}$ & Price for electricity fed into the grid & $1000 \mathrm{EUR} / \mathrm{kWh}$ \\
\hline
\end{tabular}

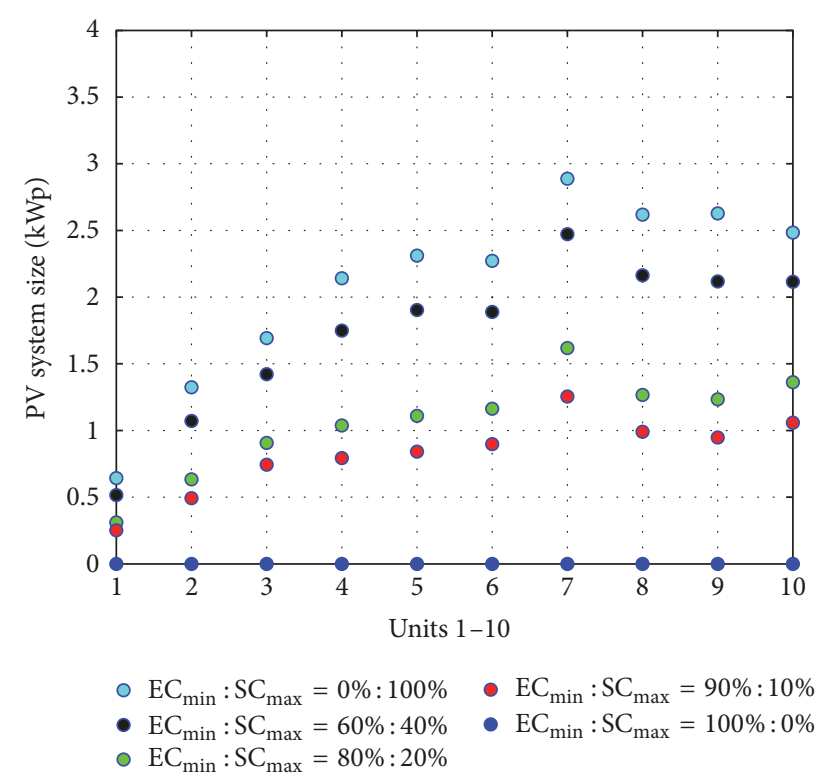

FIGURE 2: Austrian retail electricity prices: optimal PV peak capacity for the individual apartments calculated for different weighting of objective functions.

decreases, whereas the weight of maximum self-consumption rises), PV systems are installed as the goal of minimizing annual electricity costs becomes less important.

In the case of German retail electricity prices (Figure 3), there exists a cost-saving potential, which leads to PV system installation for the objective of minimizing annual electricity costs. The largest possible PV capacity is determined as optimal from a goal as low as $20 \%$ self-consumption maximization upwards. The corresponding significant costsaving potential is also shown in Figure 5. It is possible to save annual electricity costs for all cases of differently weighted optimization objectives. When referring to the results calculated for Austrian retail electricity prices in Figure 4 , it is clearly visible that annual electricity costs

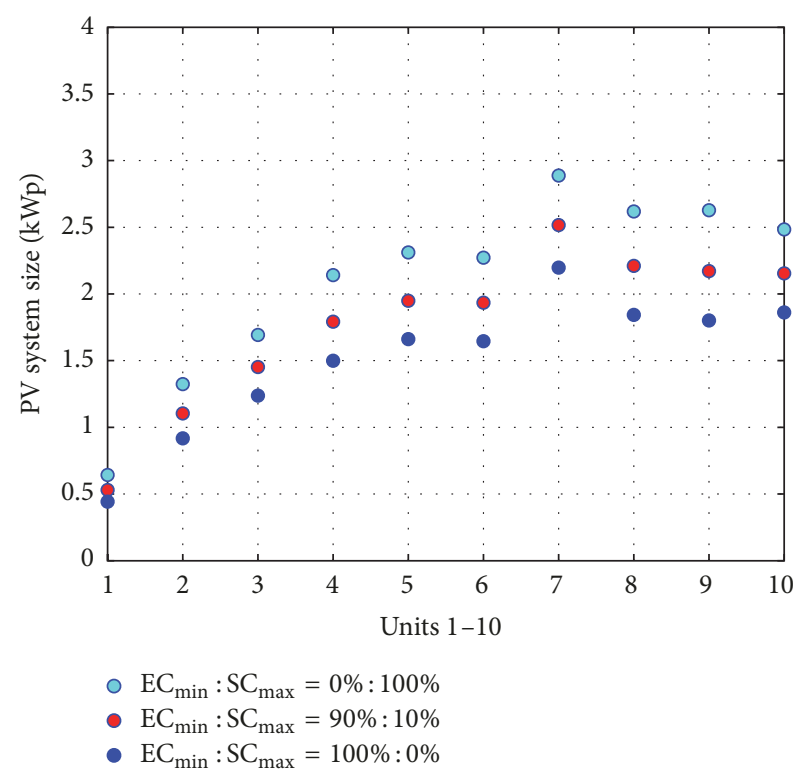

FIGURE 3: German retail electricity prices: optimal PV peak capacity for the individual apartments calculated for different weighting of objective functions.

without a PV system are lower than those with a PV system. This indicates that no cost-saving potential exists for the case of considering individual apartments.

4.2. Building Considered as Total Load: Implementation of an Optimal PV System. In this section, calculations are conducted for the building considered as total load (sum of all load profiles). For Austrian retail electricity prices, it can be seen in Figure 6 that in case of a weighting between 0 and 0.5 of the objective of minimizing annual costs (that means high importance of the objective of maximizing selfconsumption), the maximum possible $\mathrm{PV}$ system size of $21 \mathrm{~kW}_{\text {peak }}$ is required. On the contrary, for German retail electricity prices (Figure 7), the maximum possible PV 


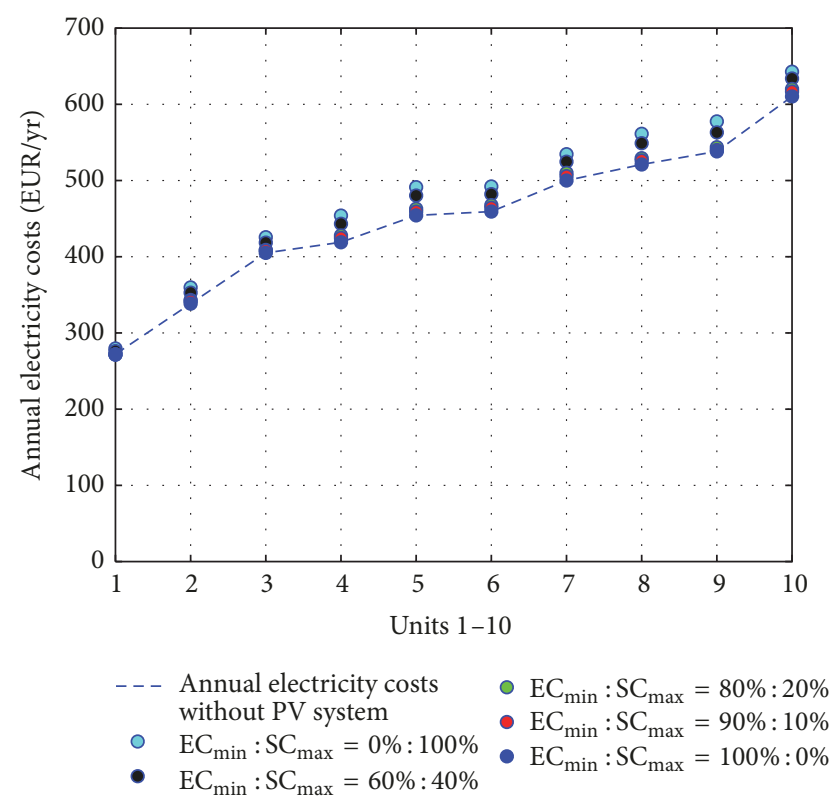

FIGURE 4: Austrian retail electricity prices: annual electricity costs for the individual apartments calculated for different weighting of objective functions.

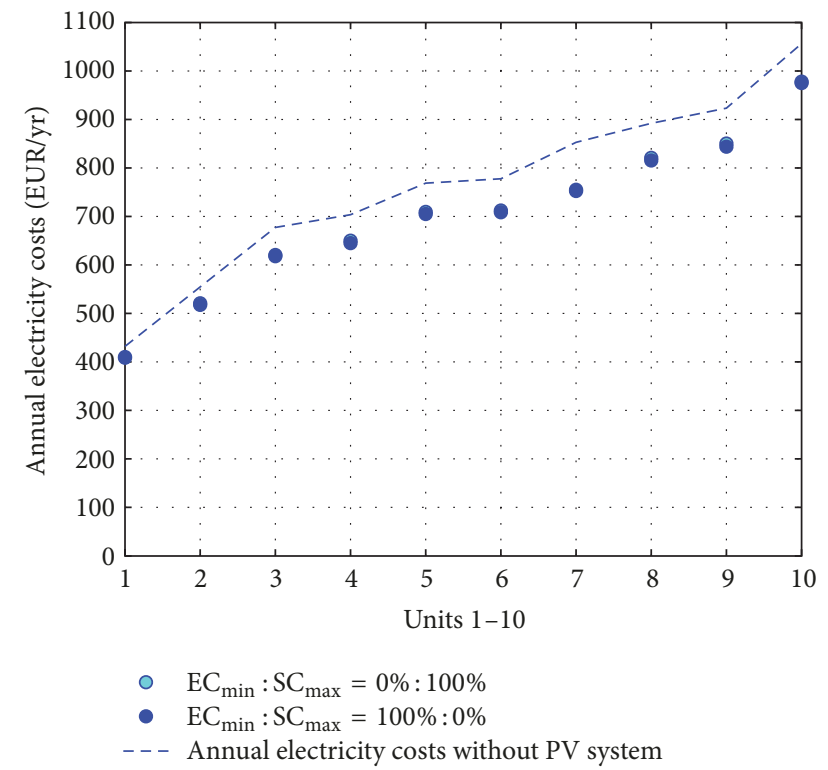

FIGURE 5: German retail electricity prices: annual electricity costs for the individual apartments calculated for different weighting of objective functions.

system size is implemented for a weighting of the objective of minimizing annual costs between 0 and 0.8 . The optimal PV system size calculated for German retail prices is generally higher, compared to the Austrian case study. Again, this shows the significant cost-saving potential of PV systems in countries with a high variable component of the retail electricity price, like Germany. Self-consumption of PV generated electricity leads to a reduction in purchase from the electricity grid. In these two case studies, the residual load

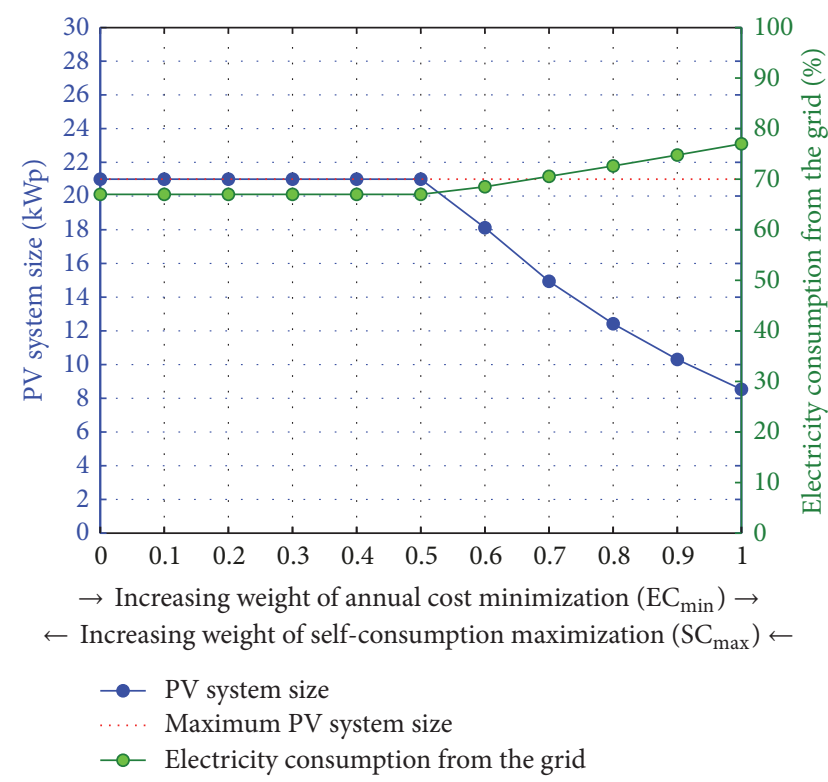

FIGURE 6: Austrian retail electricity prices: optimal PV peak capacity installed and remaining electricity consumption from the grid.

reaches about $65 \%$ (in the cases for PV system installations of $21 \mathrm{~kW}_{\text {peak }}$ ) up to $70 \%$ for German retail electricity prices and up to $77 \%$ for Austrian retail electricity prices (in the cases for an entire goal of minimizing electricity costs).

When comparing Figure 6 to the case with optimizations conducted for individual apartments in Figure 2, it can be observed that, in the case of the whole building considered as total load, a PV system is installed even in case of a $100 \%$ weighting of the cost-minimization goal. Therefore, it can be concluded that the cost-saving potential is greater for the building considered as total load than for separate treatment of the individual apartments' load profiles.

Figures 8 and 9 show the annual electricity costs of the entire building with a PV system installed, compared to the situation without a PV system. For Austrian retail electricity prices (Figure 8), the low cost-saving potential is clearly shown, as the annual difference in electricity costs for the entire building is below $100 \mathrm{EUR} / \mathrm{yr}$ for the goal of minimizing electricity costs. However, a very small costsaving potential exists for the building considered as total load and will be further explained in Section 4.2.1. In the case of German retail electricity prices (Figure 9), the annual electricity costs without a PV system are significantly higher than those with a PV system installed. This means that, even with the goal of maximizing self-consumption, electricity costs can be saved. This again demonstrates the immense cost-saving potential of PV systems when calculating with high retail electricity prices.

4.2.1. Synergy Effects between Load Profiles. As already indicated in Section 4.2, a small cost-saving potential exists in the case of Austrian retail electricity prices for the optimal dimensioning of PV systems based on the whole building's load profile, as opposed to considering individual apartments' 


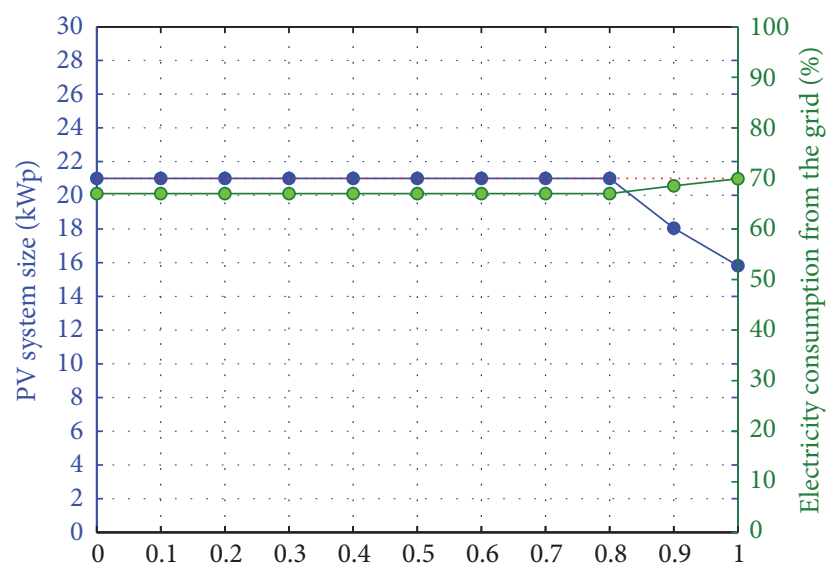

$\rightarrow$ Increasing weight of annual cost minimization $\left(\mathrm{EC}_{\min }\right) \rightarrow$

$\leftarrow$ Increasing weight of self-consumption maximization $\left(\mathrm{SC}_{\max }\right) \leftarrow$

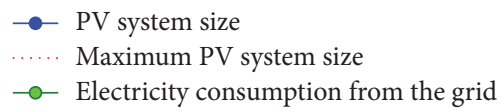

FIGURE 7: German retail electricity prices: optimal PV peak capacity installed and remaining electricity consumption from the grid.

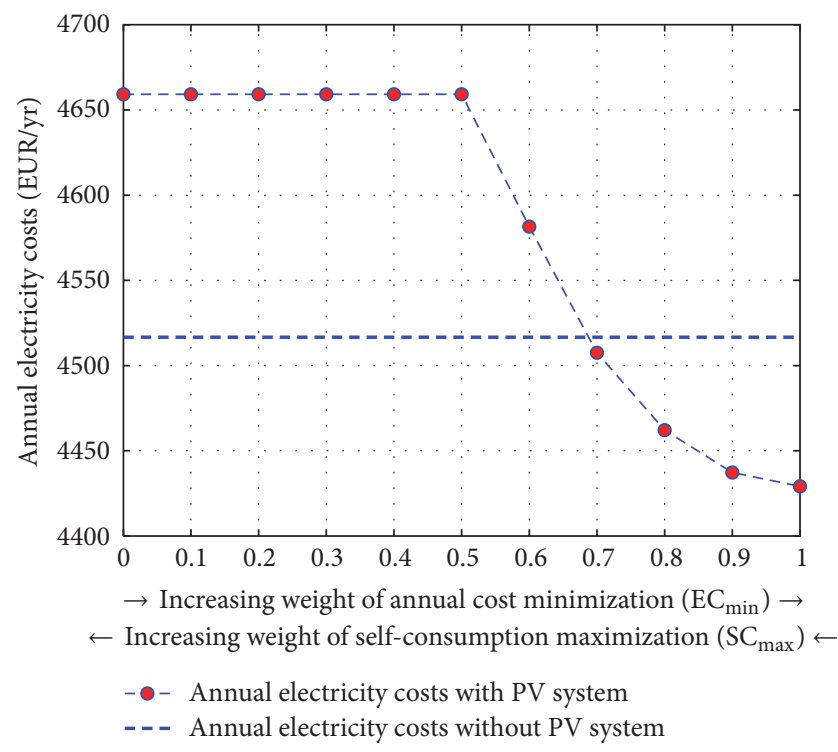

FIGURE 8: Austrian retail electricity prices: comparison of annual electricity costs with and without a PV system installed.

load profiles. In order to be able to demonstrate the existence of synergy effects between different load profiles, the sum of optimally calculated PV peak capacities for individual apartments has to be compared to the optimal PV peak capacity calculated for the building considered as total load. This means a comparison of the results of Sections 4.1 and 4.2 represented in Figures 10 and 11. Figure 10 shows that the deviation from considering individual apartments' load profiles for the minimal cost optimization (weighting of 1) to considering the building as total load results in economic viability, with a PV system of about $8.5 \mathrm{~kW}_{\text {peak }}$ installed. For Austrian retail electricity prices, as well as for German

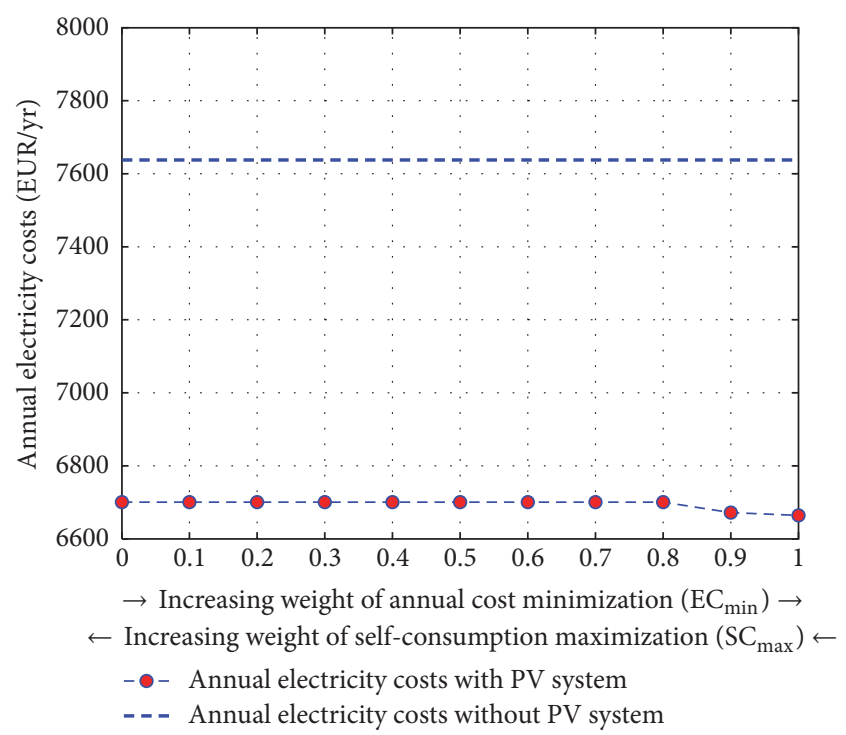

FIGURE 9: German retail electricity prices: comparison of annual electricity costs with and without a PV system installed.

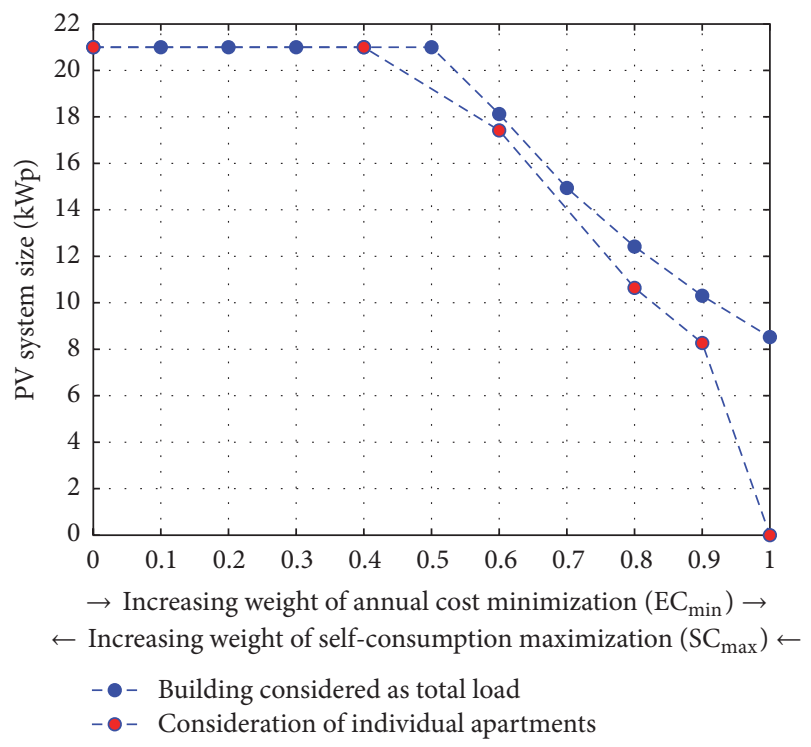

FIGURE 10: Austrian retail electricity prices: impact of synergy effects between load profiles on the optimal PV peak capacity installed.

ones, the higher the weight of maximizing self-consumption the weaker the synergy effects will be. These results suggest that it will be particularly important in the future to develop business models for shared PV systems which take into consideration the positive impact of synergies between different load profiles. Without taking synergy effects into account, the implementation of PV systems with the objective of minimizing annual electricity cost would not be possible in Austria.

4.3. Building Considered as Total Load: Implementation of an Optimal PV System and an Energy Storage Facility. The model is now extended by an energy storage facility. Figure 12 shows 


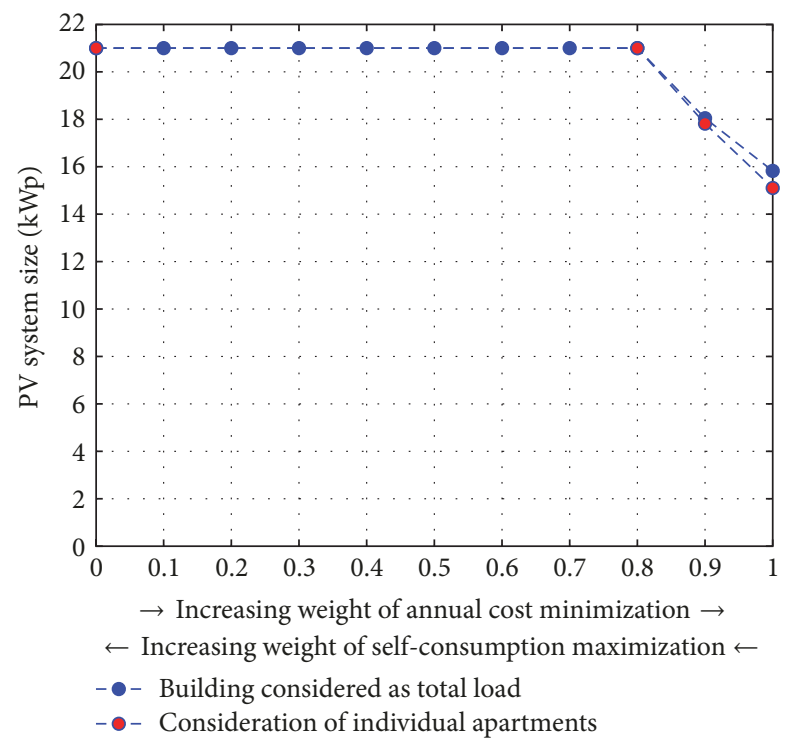

FIGURE 11: German retail electricity prices: impact of synergy effects between load profiles on the optimal PV peak capacity installed.

a comparison of the optimum storage capacities installed for different case studies, whereas Figure 13 represents the optimal PV peak capacity installed for Austrian and German retail electricity prices. The results show case studies for different investment costs for the energy storage facility. The maximal storage capacity is limited at $100 \mathrm{kWh}$. The storage facility's investment costs of $1000 \mathrm{EUR} / \mathrm{kWh}$ represent the current market price, while the lower storage facility costs of $500 \mathrm{EUR} / \mathrm{kWh}$ represent a future scenario, as investment costs of energy storage facilities are steadily decreasing.

Including an energy storage facility, the optimal PV system size (Figure 13) rises in comparison to the scenarios without storage. At low market prices of $0.03 \mathrm{EUR} / \mathrm{kWh}$, storing electricity is more profitable than feeding surplus PV electricity into the grid. The PV system size also increases with decreasing investment costs for storage facilities. In the case of Austrian retail electricity prices, it can be seen that, with $1000 \mathrm{EUR} / \mathrm{kWh}$ of investment costs, no or just a very small storage unit is installed in case of high weighting of the cost-minimization objective. The investment costs are too high to achieve any annual electricity cost savings. For larger storage capacities, investment costs have to further decrease or the variable component of the retail electricity price needs to rise. In Germany, on the contrary, with its significantly higher variable retail electricity price component (almost twice as high as in Austria), the cost-saving potential of consuming self-generated PV electricity is significantly higher. This leads to a greater expansion of PV system size and storage capacity.

Finally, an annual electricity cost comparison for the different case studies with the building considered as total load is given in Figures 14 and 15. Figure 15 indicates that in the case of German retail electricity prices the costsaving potential is considerable. It is possible to save costs in comparison to the initial situation up to a certain extent even when implementing large energy storage facilities with

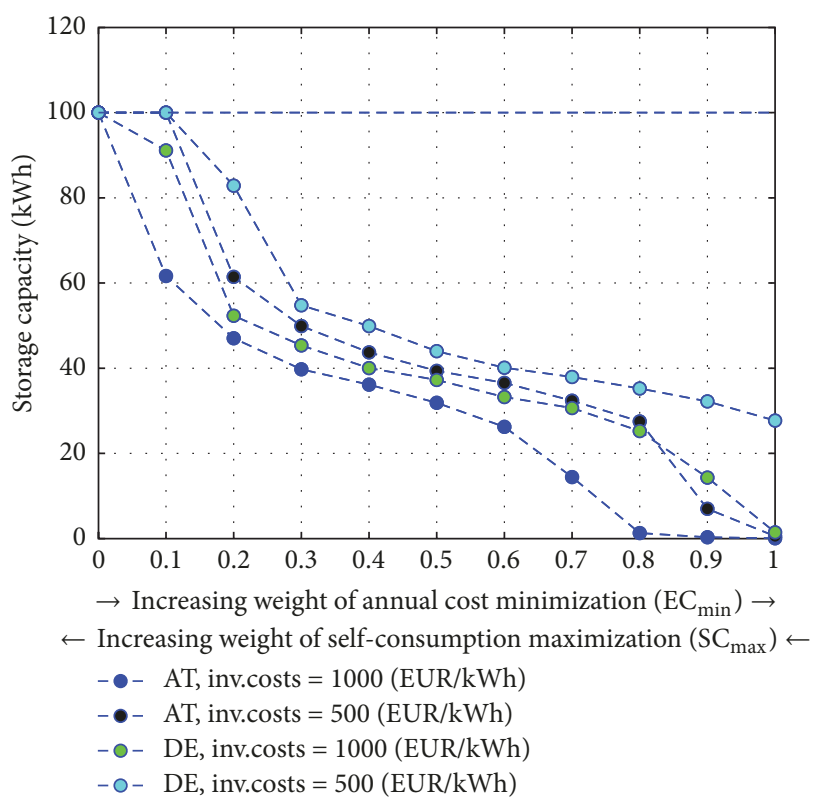

FIGURE 12: Comparison of optimally dimensioned storage capacity for different case studies. The maximal storage capacity is limited at $100 \mathrm{kWh}$, marked by the dashed blue line.

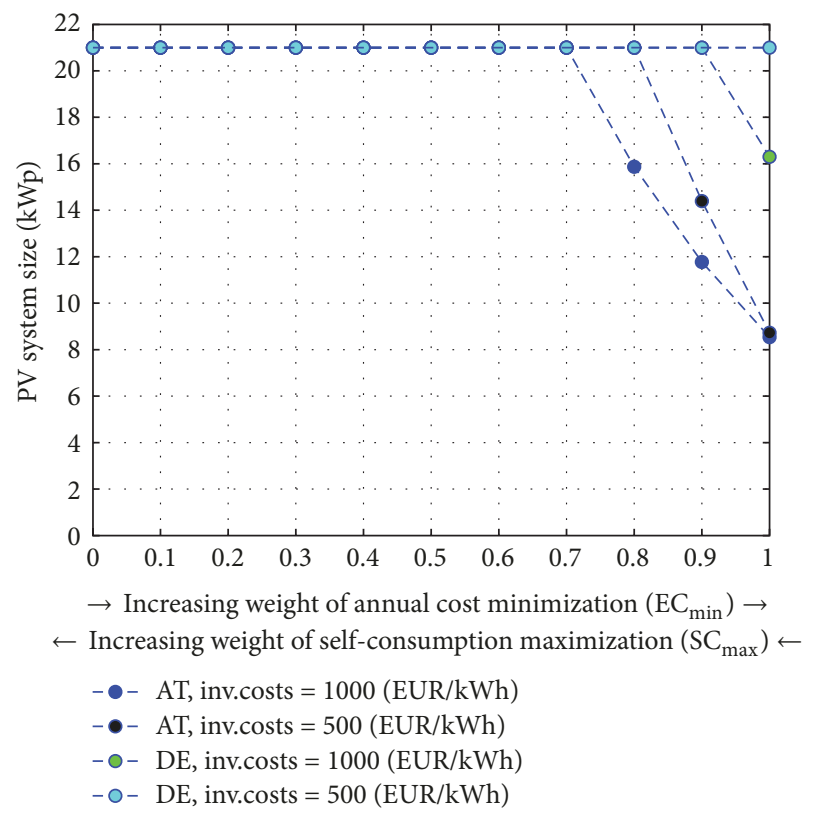

FIGURE 13: Comparison of optimally dimensioned PV peak capacity for different case studies.

the corresponding investment costs. With Austrian retail electricity prices, on the contrary, no energy costs can be saved by implementing an energy storage facility, which is illustrated in Figure 14.

\section{Synthesis of Results and Business Models}

5.1. Tenants' Revenues versus Additional Costs in Case of PV System Installation. This section compares the cost difference 


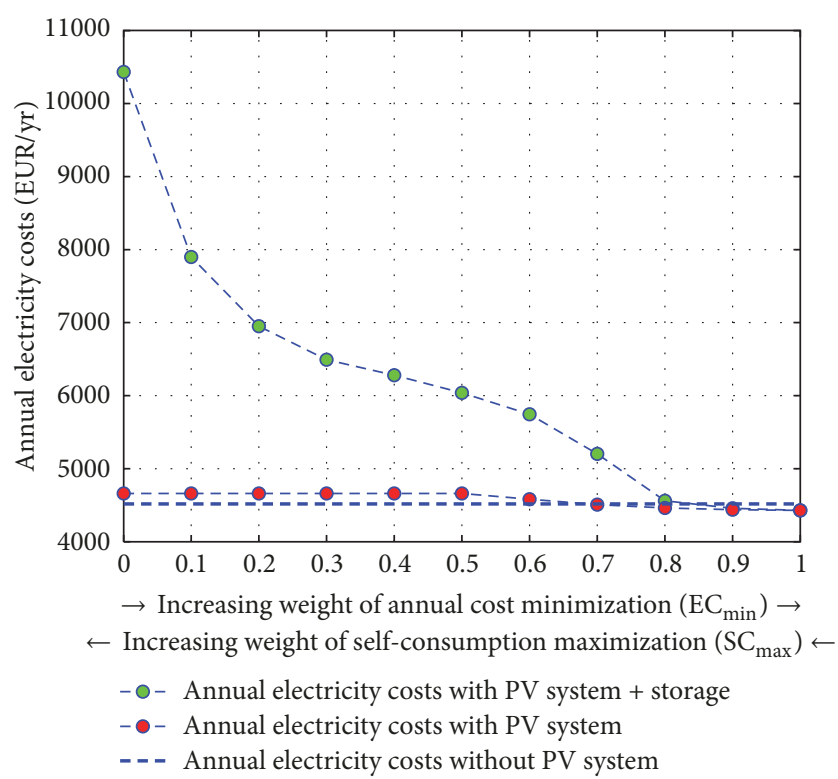

FIGURE 14: Austrian retail electricity prices: comparison of annual electricity costs.

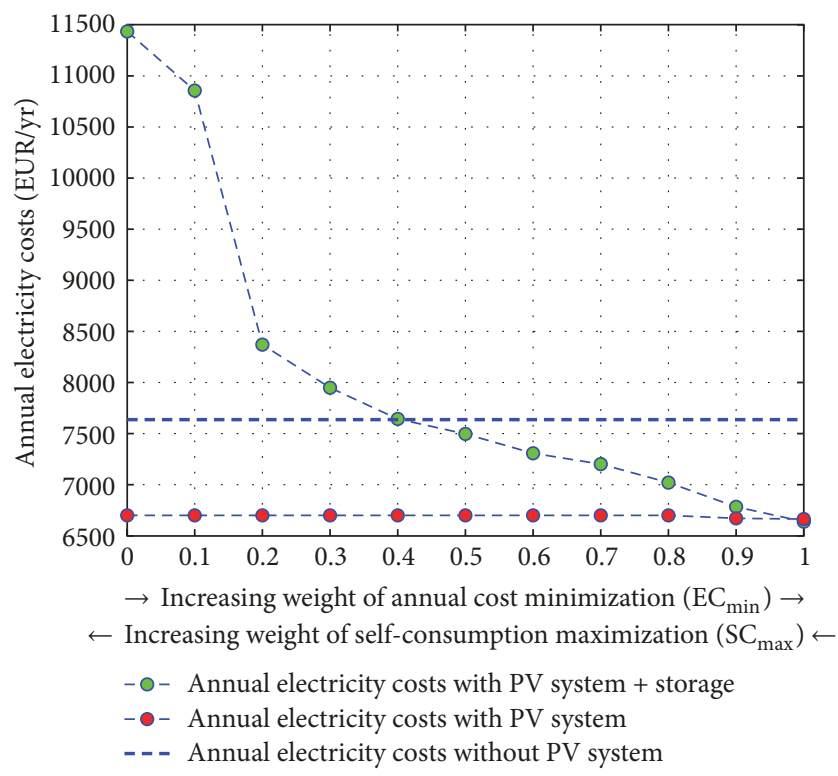

FIGURE 15: German retail electricity prices: comparison of annual electricity costs.

between the initial annual electricity costs (without a PV system) and those with a PV system implemented, presented for the individual apartments, as well as for the entire building. Results are shown for the Austrian and German retail electricity prices, depending on the self-consumption. It can be seen in Figure 16 that, in the case of Austrian retail electricity prices and consideration of individual apartments, profitability is not given yet, since the cost difference

$$
C_{\text {diff }}=C_{\text {withoutPV }}-C_{\text {withPV }}
$$

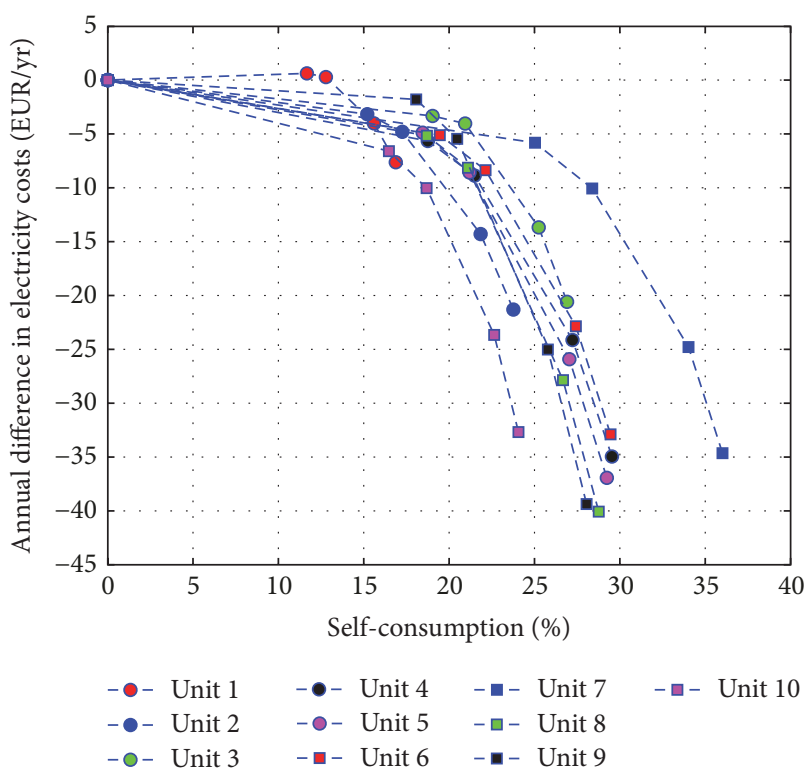

FIGURE 16: Austrian retail electricity prices, consideration of individual apartments: annual differences in electricity costs with and without a PV system.

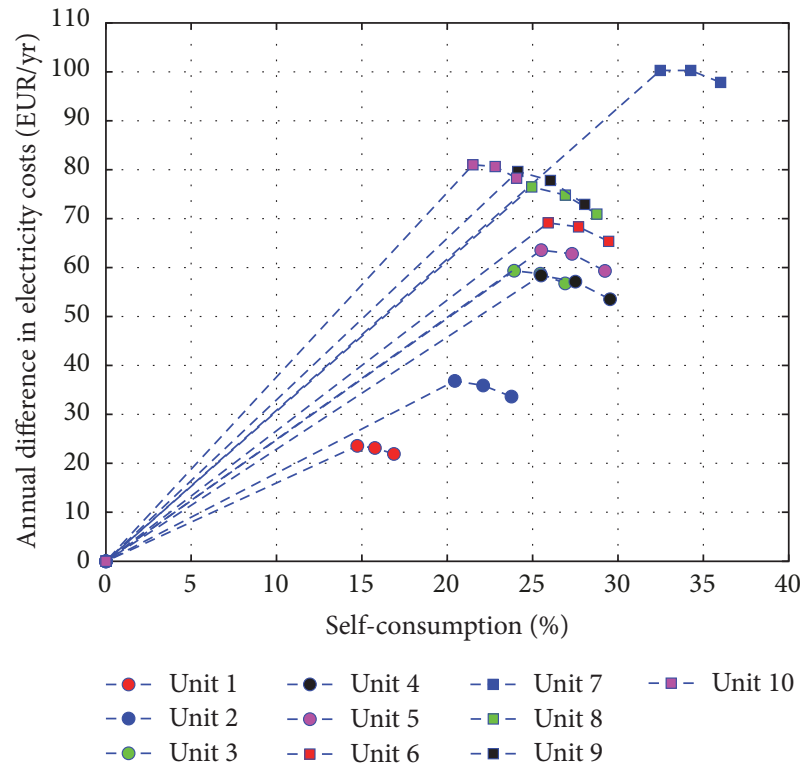

FIGURE 17: German retail electricity prices, consideration of individual apartments: annual differences in electricity costs with and without a PV system.

is negative. In the case of negative cost differences, tenants have slightly higher annual costs when implementing a PV system than without one. However, the graph also shows that, in case of a self-consumption rate of about $30 \%$, just 40 EUR of additional costs occur, compared to the initial situation without a PV system. Therefore, the profitability gap is already small when considering individual load profiles.

The case study with German retail electricity prices shown in Figure 17 shows noticeably different results. This can be explained by the fact that, due to the high variable 


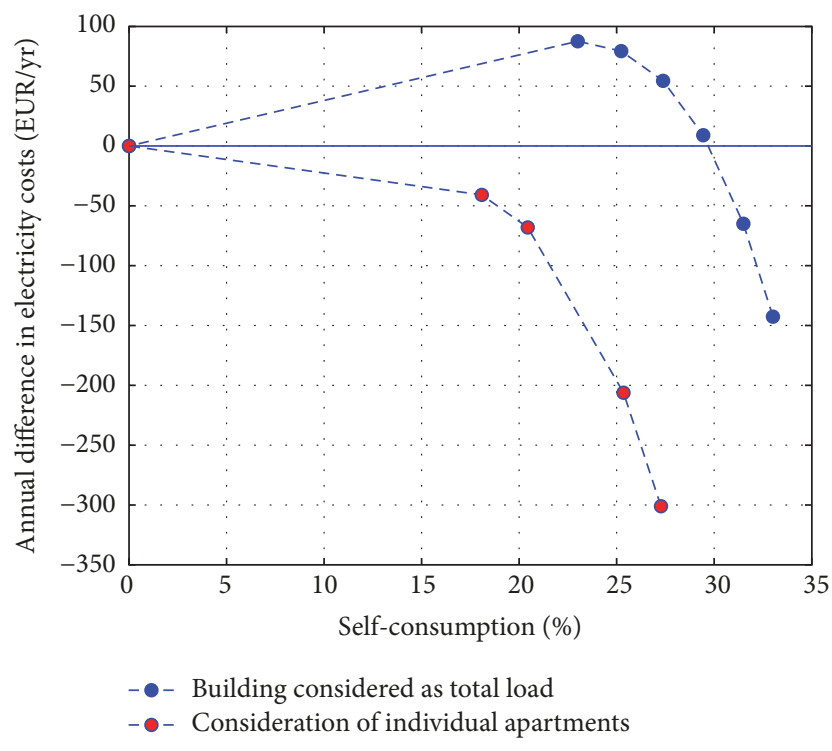

FIGURE 18: Austrian retail electricity prices, comparison between buildings considered as total load and consideration of individual apartments' load profiles: annual differences in electricity costs with and without a PV system. The border between profitability and no profitability is emphasized by the blue solid line.

component of the retail electricity price in Germany, the usage of the PV systems within a shared PV concept is economically viable, which leads to positive cost differences and therefore savings in the electricity bill. The positive cost difference drops slightly with higher self-consumption rates, since investment costs also rise with PV system sizes.

Figures 18 and 19 show the discrepancies in the calculations of annual electricity costs, based on the sum of cost differences of all apartments versus the cost difference for the entire building considered as total load. It can be seen clearly that, with synergy effects between individual load profiles taken into account (building considered as total load), significantly more costs can be saved in the case of German retail electricity prices. In the case of Austrian retail electricity prices, a small amount of costs can be saved or less additional costs are incurred.

\subsection{Tenants' Revenues versus Additional Costs in Case of} $P V$ System and Energy Storage Facility Installation. Figures 20 and 21 show the differences between the initial annual electricity costs (neither PV system nor storage) and the annual electricity costs including an optimally dimensioned PV system and energy storage facility for the building considered as total load:

$$
C_{\text {diff }}=C_{\text {withoutPV\&St }}-C_{\text {withPV\&St }} .
$$

In the case of Austrian retail electricity prices (Figure 20), it can be seen that profitability is given just at the very beginning of the curve, where no or just a small storage unit is installed (compared to Figure 12). As soon as the weight of maximizing self-consumption rises, the annual costs with PV system and storage become significantly higher than the

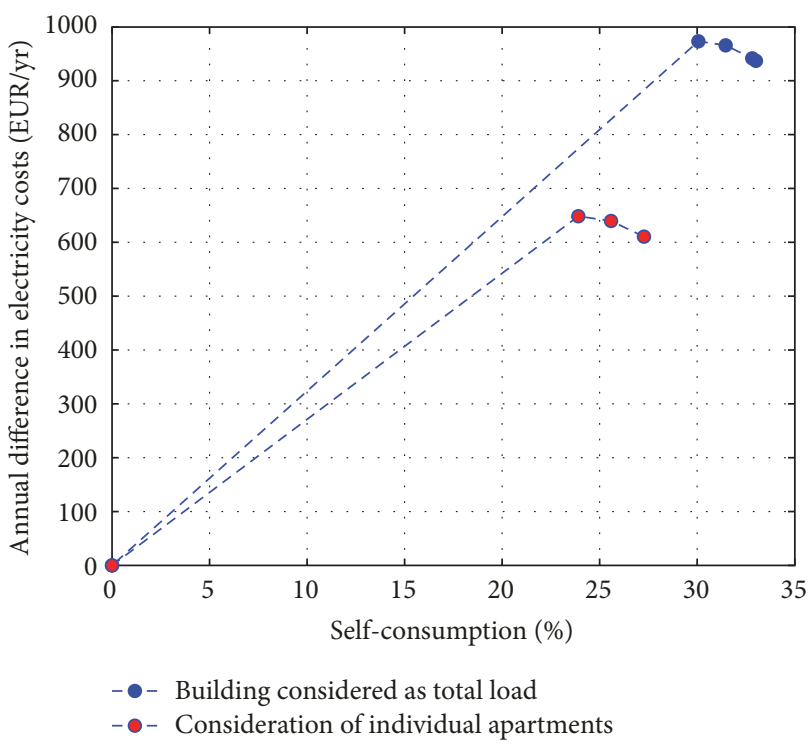

FIGURE 19: German retail electricity prices, comparison between buildings considered as total load and consideration of individual apartments' load profiles: annual differences in electricity costs with and without a PV system.

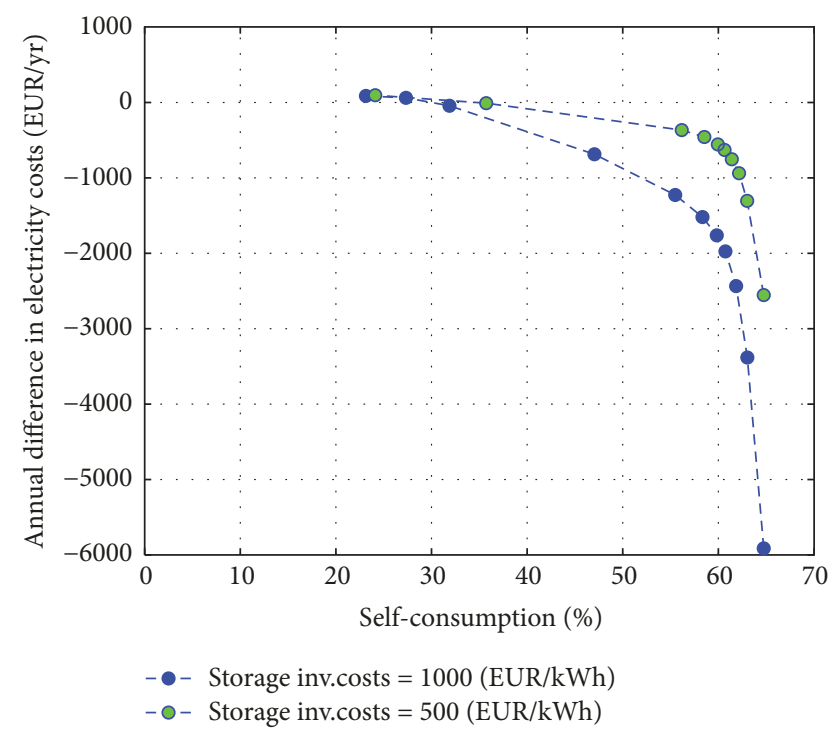

FIGURE 20: Austrian retail electricity prices: annual electricity cost difference.

costs without PV system and storage, as the cost difference becomes negative. Even with lower investment costs for an energy storage facility, profitability is not achieved yet; the negative cost difference just becomes smaller. To increase profitability of such systems in Austria, either the costs for PV systems and storage facilities have to drop further, or the variable part of the retail electricity price has to be raised. In the case of German retail electricity prices (Figure 21), profitability is achieved to a great extent. Only in cases with a high weight of self-consumption maximization do the costs for implementing large PV and storage capacities lead to 


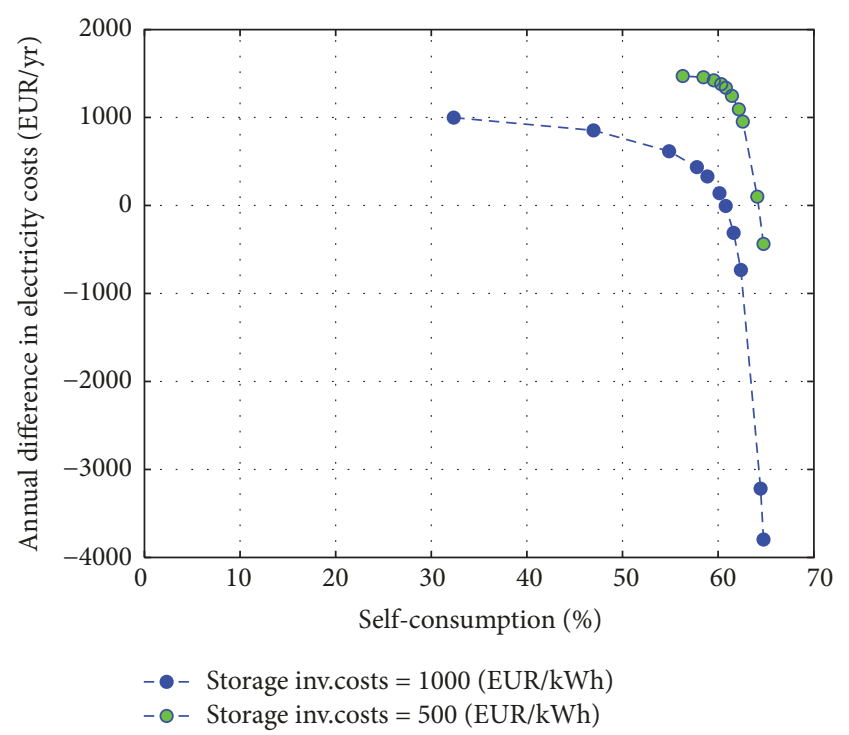

FIGURE 21: German retail electricity prices: annual electricity cost difference.

negative cost differences. For all other cases, the significant cost-saving potential through self-consumed electricity leads to positive cost differences and thus profitability.

\subsection{Investors' Revenues and Tenants' Additional Costs/Savings} for Different Values of Weighted Average Cost of Capital. When addressing multiapartment buildings, it is assumed that the investor and the landlord are the same person. It is expected that almost all property owners only invest in a shared PV concept if a reasonable rate of return can be expected. The investment costs for the PV system borne by the property owner are incurred at the time of the PV system's installation. They are split into a fixed-cost component for installation, irrespectively of the PV system's size, and a variable component (depending on the peak capacity installed), shown in

$$
C_{\text {inv }}=c_{\text {fix } \_ \text {pv }}+i_{0 \mathrm{pv}} \cdot P_{\text {peak }}
$$

For the property owner, it is important to compensate for these initial expenses through increased operating and rental costs. The landlord chooses a corresponding WACC (weighted average cost of capital) based on the value of expected profit or the risk accepted. The WACC does account not only for the amount of investors' revenues but also for the increase in operating/rental costs for the tenants (monetary compensation for the landlord's investment costs). Calculations based on a high WACC lead to high annual payments for tenants and thus higher income for the landlord (shown in Figures 22 and 23). For tenants, the participation in shared PV electricity tenant-models becomes less economical with an increasing WACC. The situation for tenants is shown in Figures 24 and 25, where the annual electricity cost differences between the situations with and without a PV system $\left(C_{\text {diff }}=C_{\text {withoutPV }}-C_{\text {withPV }}\right)$ are calculated for varying WACCs. It can be seen that the economic viability for tenants

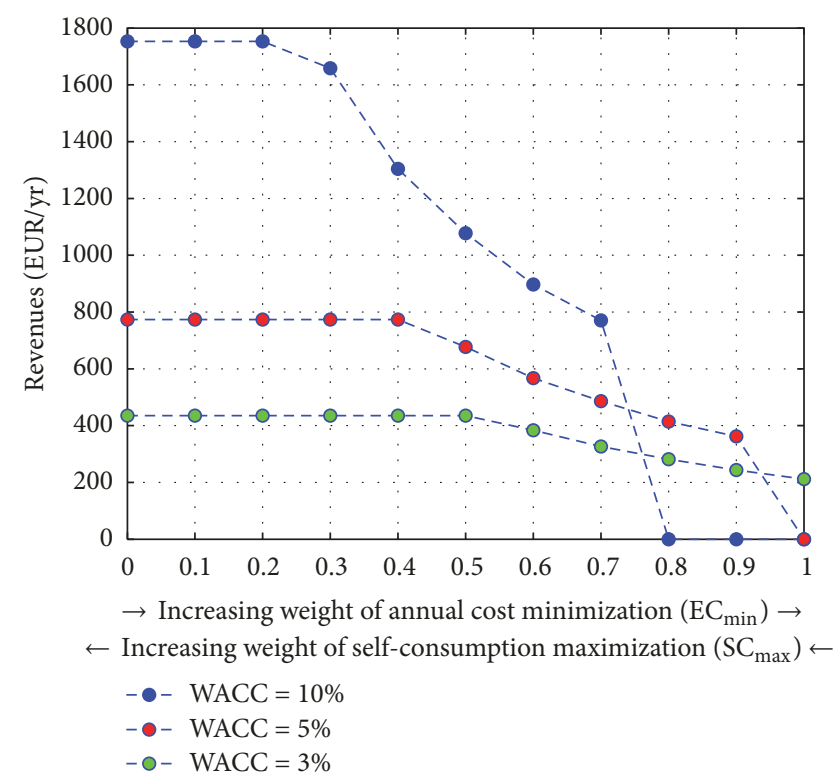

FIGURE 22: Austrian retail electricity prices: revenues for property owners for different WACCs.

drops with higher WACCs. In the case of Austrian retail electricity prices (Figure 24), cost reduction for tenants can be achieved, to a small extent, only for low WACCs of $3 \%$. In the case of higher WACCs (5\% and 10\%), the difference in annual electricity costs is clearly negative. This means that tenants incur additional costs. The case study with German retail electricity prices shown in Figure 25 indicates that profitability for tenants is possible for a rate of return of $5 \%$ as well. Even in the case of a WACC of $10 \%$, tenants profit from participating in the shared PV electricity tenant-model for heavy weighting of minimizing annual electricity costs.

5.4. Business Models. This section proposes two business models commonly used in Germany, as well as two possible business models for implementing shared PV systems in Austria.

5.4.1. State-of-the-Art Business Model in Germany. In order to use self-generated PV electricity in multiapartment buildings, energy suppliers (for example, Polarstern [37]) supporting shared electricity concepts have to be found. Two main business models are offered: Enabling and Contracting. In the case of Enabling, the PV system owner sells the entire amount of generated PV electricity to the energy supplier. The latter buys PV electricity, in case it is used within a shared PV concept, at a higher price than commonly paid for feed-in from PV systems. Residents who participate in the shared PV electricity concept buy electricity at a lower price than usually paid for electricity purchased from the grid. To cover the residual load, they are supplied with energy from the electricity grid. The advantage of this business model is the high degree of hedging for the owners, since the energy supplier purchases the entire amount of electricity generated by the PV system, regardless of the number of tenants 


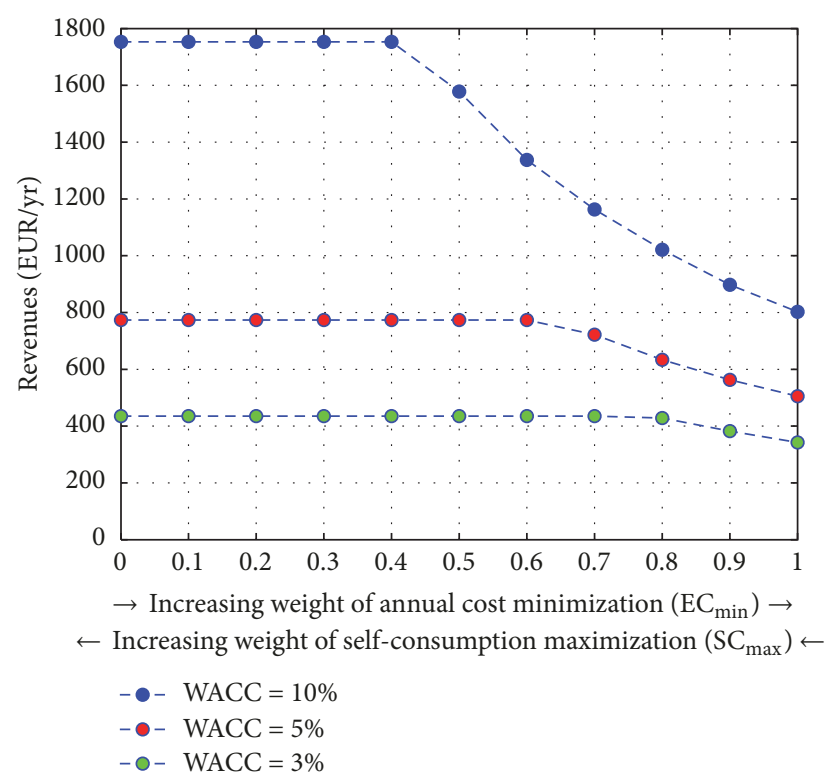

FIGURE 23: German retail electricity prices: revenues for property owners for different WACCs.

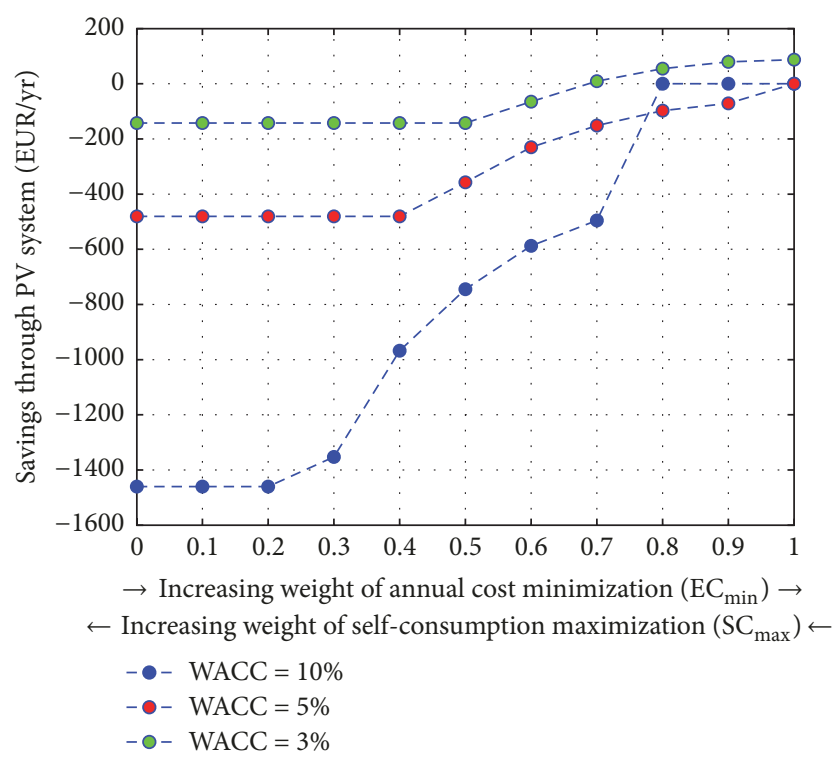

FIGURE 24: Austrian retail electricity prices: annual electricity costs for the building considered as total load.

participating in the shared PV concept. Besides, this business model guarantees profitability for the tenant. In the business model of Contracting, the energy supplier establishes the shared electricity concept (mostly PV in combination with $\mathrm{CHP}$ ), bearing all costs, and supplies tenants with electricity at attractive prices. This business model is based on long-term contracts with the landlords, who lease the space needed to install electricity generation units.

5.4.2. Static Allocation of Generated PV Electricity. The landlord/investor invests in a PV system of optimal size, according to individual apartments' load profiles. The investment in

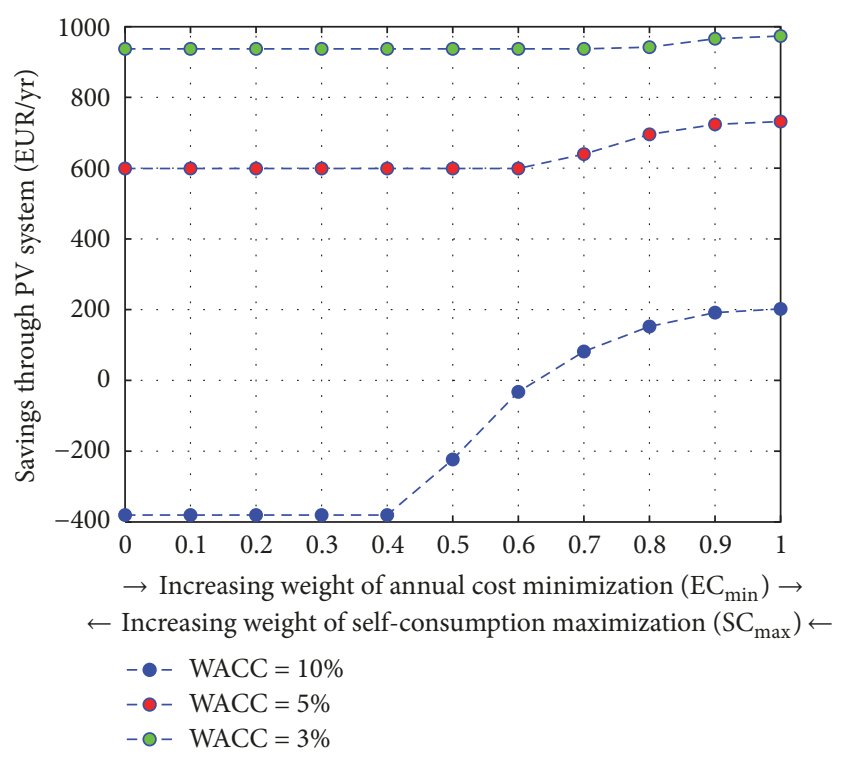

FIGURE 25: German retail electricity prices: annual electricity costs for the building considered as total load.

installing the PV system for shared use is amortized through increasing operating and rental costs. Tenants participating in the shared PV concept receive a proportional amount of electricity generated by the PV system. If the individual tenants do not use the entire electricity allocated to them, the surplus is fed into the grid, whereby certain revenues, depending on the price for surplus feed-in, can be achieved. The residual load is covered by electricity purchase from the grid (Figure 26). In the case of using static allocation of shared PV electricity as a business model, the legislative amendment obliges the grid operator to allocate the electricity generated by the PV system to the individual apartments correctly. For this purpose, appropriate metering devices have to be installed by the grid operator. However, it is not necessary to replace measuring devices instantly for static allocation, as netting out over the year is also an option [1]. Therefore, an advantage of this business model is that old metering devices do not have to be replaced immediately. Furthermore, the static allocation of electricity, as well as billing, is easy to understand for the tenants. This prevents mistrust. However, synergy effects between load profiles are not taken into account by using static allocation. This reduces the costsaving potential for tenants. From a landlord's point of view, a problem of this concept is the high risk of tenant changes. If new tenants decide to drop out from the shared PV electricity scheme, the landlord/investor has to feed the electricity surplus into the grid and thus receives lower revenues.

5.4.3. Dynamic Allocation of Generated PV Electricity. The landlord/investor invests in a PV system of optimal size according to the sum of the participating tenants' load profiles. The PV system is amortized over the years through increased operating and rental costs. Tenants receive PV electricity dynamically. This means PV electricity consumption is not limited to a proportionate amount allocated to the 


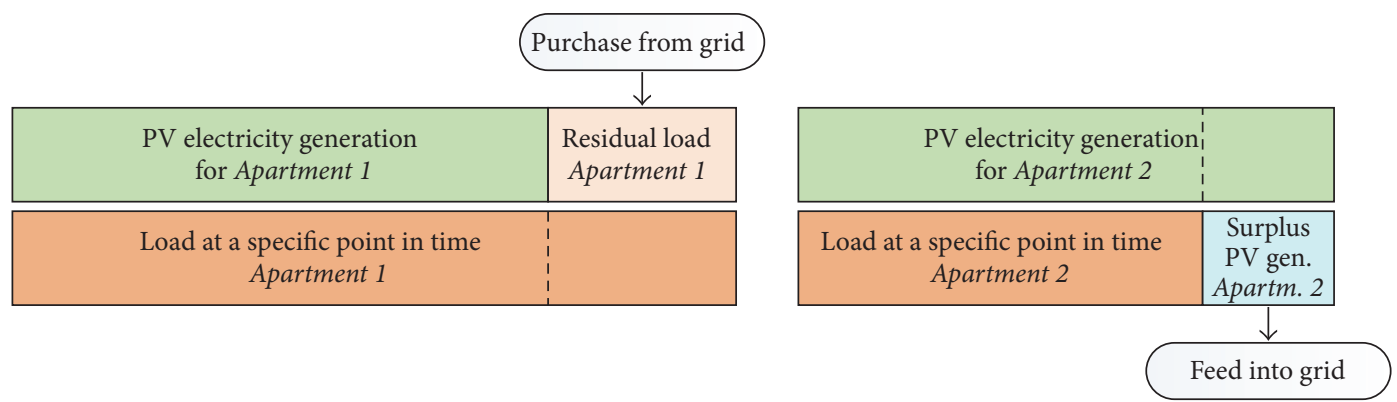

FIGURE 26: Static allocation of PV generation: example of two apartments.

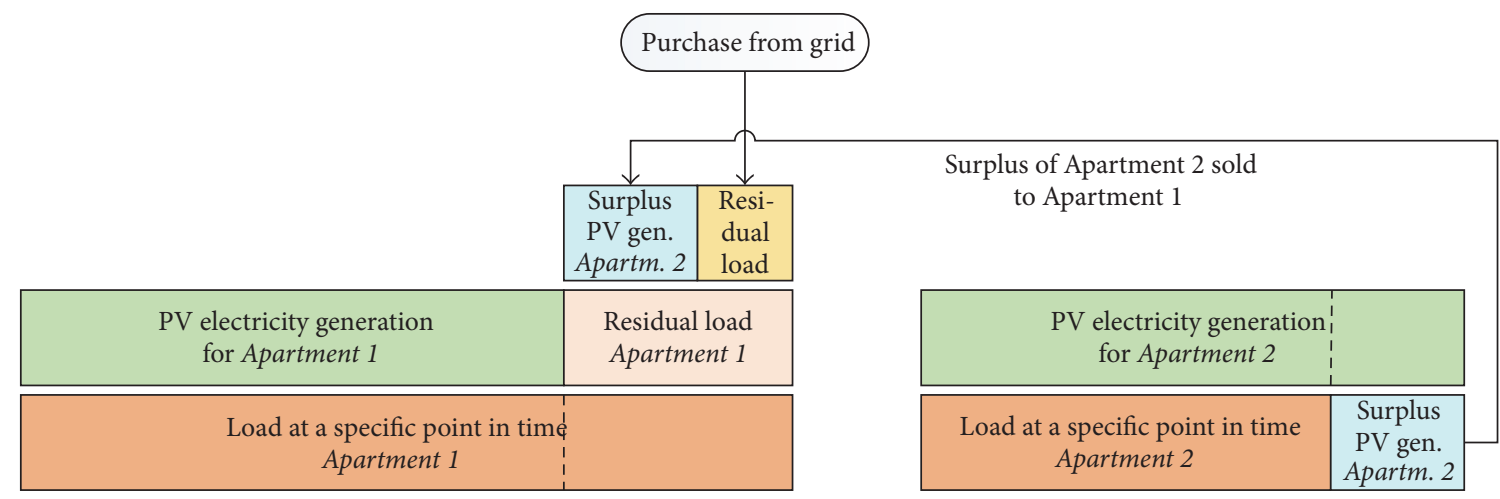

FIgURE 27: Dynamic allocation of PV generation: example of two apartments.

individual households. In the event that, at specific times, the energy requirements of a tenant are lower than average, other tenants can use the surplus thus created in order to cover their load. The new emerging residual load is then covered by electricity from the grid (Figure 27). The legislative amendment obliges the grid operator to allocate electricity generated by the PV system to the individual apartments dynamically. For this purpose, appropriate metering devices have to be installed by the grid operator. The bigger costsaving potential and the higher self-consumption rate are advantageous for the tenants, as synergy effects between different load profiles are taken into account. A negative aspect is that, as dynamically allocated electricity is not directly traceable for tenants, it can lead to distrust. Furthermore, in contrast to the static allocation model, old metering devices have to be exchanged immediately; otherwise, the business model of dynamic allocation cannot be implemented. Risks for landlords are the same as those described in Section 5.4.2 for static allocation of PV electricity.

5.4.4. Open Questions and Future Business Models. The business model of static allocation (Section 5.4.2) is easy in terms of billing. On the contrary, the business model of dynamic allocation of PV electricity (Section 5.4.3) involves issues concerning the applicable accounting methods. These issues need to be addressed in the near future, if we are to successfully implement shared PV systems in multiapartment buildings on a large scale. Not least of all, billing is a sensitive topic for residents participating in shared PV concepts. Different tariff models will emerge in the future.

Moreover, in order to promote a widespread use of shared PV systems, it will be necessary to revise and further expand the business model of dynamic allocation. Interbuilding PV electricity trade will become possible in the future, not only to further increase the self-consumption rate and the costsaving potential, but also to allow the integration of electric vehicle charging stations. With the inclusion of electric vehicle charging stations, also used by third parties, accounting and billing methods will become even more complicated and, therefore, require special focus in future analyses.

\section{Conclusions}

The results of this paper show that the economic viability of shared PV systems strongly depends on the absolute value of the variable component of the retail electricity price. For Germany, a country with a high retail electricity price (due to high renewable energy surcharges), the concept is clearly profitable, whereas economic viability is nonexistent or marginal in Austria. Due to the limited profitability in Austria, no profitability in case of matching PV generation and loads for individual apartments, and a small cost-saving potential in the case of aggregation of all apartments' loads, it is important to implement business models, resulting in a win-win situation for both tenants and landlords or residents in general. To better intertwine the shared PV 
concept with the energy system itself, further adjustments of the legal framework will be inevitable in the near future, in order to improve and expand the basic business models. In addition to legislative amendments, solutions for tenants refusing participation in the shared PV concept have to be developed, as do regulations to deal with tenant changes.

\section{Abbreviations}

$\begin{array}{ll}C_{\text {diff }}: & \text { Difference in annual electricity costs } \\ C_{\text {inv }}: & \text { [EUR/yr] } \\ & \text { Total investment costs for PV system } \\ C_{\text {other }}: & \text { [EUR] } \\ C_{\text {pv_b }}: & \text { Other cost terms [EUR/yr] } \\ & \text { Annual costs, dependent on existence of } \\ C_{\text {pv_peak }}: & \text { PV system [EUR/yr] } \\ & \text { Annual costs, dependent on installed PV } \\ C_{\text {storage }}: & \text { peak power [EUR/yr] } \\ C_{\text {var }}: & \text { Storage's annual costs [EUR/yr] } \\ C_{\text {withPV }}: & \text { Quantity-dependent costs [EUR] } \\ & \text { Annual electricity costs with PV system } \\ C_{\text {withPV\&St }}: & \text { installed [EUR/yr] } \\ & \text { Annual electricity costs with PV system } \\ & \text { and storage facility installed [EUR/yr] } \\ C_{\text {withoutPV }}: & \text { Annual electricity costs with no PV } \\ & \text { system installed [EUR/yr] } \\ C_{\text {withoutPV\&St }}: & \text { Annual electricity costs with no PV system } \\ & \text { and no storage facility installed [EUR/yr] } \\ c_{\text {clean }}: & \text { Electricity generated by PV system } \\ c_{\text {fix_elec }:}: & \text { [kWh/kW peak }\end{array}$

$c_{\mathrm{op}}: \quad$ Operating costs of PV system [EUR/yr]

$c_{\text {var_elec }}$ Variable component of retail electricity price [EUR/kWh]

$\gamma$ : Weighting factor of different goals within multiobjective optimization

$e_{\text {in }}: \quad$ Energy fed into the storage facility [kWh]

$e_{\text {out }}$ : Energy discharged from storage facility [kWh]

$e_{\text {grid }}: \quad$ Electricity purchased from the grid [kWh]

$e_{\text {load }}:$ Load [kWh]

$e_{\text {pv2grid }}$ : Electricity fed by PV system into the grid $[\mathrm{kWh}]$

$e_{\text {pv2load }}$ : Electricity from PV system used to cover the load [kWh]

$\eta_{\text {storage }}$ : Storage facility's degree of efficiency

$i_{0 \mathrm{pv}}: \quad$ Specific investment costs of PV system $\left[\mathrm{EUR} / \mathrm{kW}_{\text {peak }}\right]$

$i_{0 \text { storage }}:$ Specific investment costs of energy storage facility [EUR/kWh]

$p_{\text {feed_in }}$ Price for electricity fed into the grid [EUR/kWh].

\section{Conflicts of Interest}

The authors declare that there are no conflicts of interest regarding the publication of this paper.

\section{References}

[1] Republik Österreich, Bundesgesetzblatt I Nr.108/2017. https:// www.ris.bka.gv.at/Dokument.wxe?Abfrage=BgblAuthDokumentnummer=BGBLA_2017_I_108, 2017.

[2] P. Asmus, "Microgrids, virtual power plants and our distributed energy future," The Electricity Journal, vol. 23, no. 10, pp. 72-82, 2010.

[3] S. M. Nosratabadi, R.-A. Hooshmand, and E. Gholipour, "A comprehensive review on microgrid and virtual power plant concepts employed for distributed energy resources scheduling in power systems," Renewable \& Sustainable Energy Reviews, vol. 67, pp. 341-363, 2017.

[4] N. Nikmehr, S. Najafi-Ravadanegh, and A. Khodaei, "Probabilistic optimal scheduling of networked microgrids considering time-based demand response programs under uncertainty," Applied Energy, vol. 198, pp. 267-279, 2017.

[5] J. Pascual, J. Barricarte, P. Sanchis, and L. Marroyo, "Energy management strategy for a renewable-based residential microgrid with generation and demand forecasting," Applied Energy, vol. 158, pp. 12-25, 2015.

[6] N. E. Koltsaklis, M. Giannakakis, and M. C. Georgiadis, "Optimal energy planning and scheduling of microgrids," Chemical Engineering Research and Design, 2017.

[7] G. Liu, M. Starke, B. Xiao, X. Zhang, and K. Tomsovic, "Microgrid optimal scheduling with chance-constrained islanding capability," Electric Power Systems Research, vol. 145, pp. 197206, 2017.

[8] C. Phurailatpam, B. S. Rajpurohit, and L. Wang, "Planning and optimization of autonomous DC microgrids for rural and urban applications in India," Renewable \& Sustainable Energy Reviews, vol. 82, pp. 194-204, 2018. 
[9] S. R. Sivarasu, E. Chandira Sekaran, and P. Karthik, "Development of renewable energy based microgrid project implementations for residential consumers in India: Scope, challenges and possibilities," Renewable \& Sustainable Energy Reviews, vol. 50, pp. 256-269, 2015.

[10] D. Gandini and A. T. de Almeida, "Direct current microgrids based on solar power systems and storage optimization, as a tool for cost-effective rural electrification," Journal of Renewable Energy, vol. 111, pp. 275-283, 2017.

[11] G. Lo Basso, B. Nastasi, F. Salata, and I. Golasi, "Energy retrofitting of residential buildings-How to couple Combined Heat and Power (CHP) and Heat Pump (HP) for thermal management and off-design operation," Energy and Buildings, vol. 151, pp. 293-305, 2017.

[12] H. Ren and W. Gao, "Economic and environmental evaluation of micro CHP systems with different operating modes for residential buildings in Japan," Energy and Buildings, vol. 42, no. 6, pp. 853-861, 2010.

[13] G. Comodi, A. Giantomassi, M. Severini et al., "Multiapartment residential microgrid with electrical and thermal storage devices: Experimental analysis and simulation of energy management strategies," Applied Energy, vol. 137, pp. 854-866, 2015.

[14] C. Marnay, G. Venkataramanan, M. Stadler, A. S. Siddiqui, R. Firestone, and B. Chandran, "Optimal technology selection and operation of commercial-building microgrids," IEEE Transactions on Power Systems, vol. 23, no. 3, pp. 975-982, 2008.

[15] N. Liu, Q. Chen, J. Liu et al., "A Heuristic Operation Strategy for Commercial Building Microgrids Containing EVs and PV System," IEEE Transactions on Industrial Electronics, vol. 62, no. 4, pp. 2560-2570, 2015.

[16] N. Liu, X. Yu, C. Wang, and J. Wang, "Energy Sharing Management for Microgrids with PV Prosumers: A Stackelberg Game Approach," IEEE Transactions on Industrial Informatics, vol. 13, no. 3, pp. 1088-1098, 2017.

[17] O. Saadeh, Microgrids Flourishing in Spite of Regulatory Barriers: Developers Look to Utility Projects as Regulatory Ambiguity Hinders Private-Sector Growth, 2015, https://www.greentechmedia.com/articles/read/microgrids-flourishing-in-spite-ofregulatory-barriers\#gs.u8JTKCg.

[18] C. Walsh, Microgrid Regulatory Policy in the US, 2015, https://www.civicsolar.com/support/installer/articles/microgrid-regulatory-policy-us.

[19] Task Force of Maryland, http://energy.maryland.gov/documents/MarylandResiliencyThroughMicrogridsTaskForceReport_000.pdfResiliency through Microgrids, 2014.

[20] A. Aram, Microgrid Market in the USA, 2015, http://www.hitachi.com/rev/archive/2017/r2017_05/pdf/P26-30_Global.pdf.

[21] E. Biyik, M. Araz, A. Hepbasli et al., "A key review of building integrated photovoltaic (BIPV) systems," Engineering Science and Technology, an International Journal, vol. 20, no. 3, pp. 833858, 2017.

[22] R. Singh and R. Banerjee, "Estimation of rooftop solar photovoltaic potential of a city," Solar Energy, vol. 115, pp. 589-602, 2015.

[23] P. Campos, L. Troncoso, P. D. Lund, C. Cuevas, A. Fissore, and R. Garcia, "Potential of distributed photovoltaics in urban Chile," Solar Energy, vol. 135, pp. 43-49, 2016.

[24] R. F. C. Miranda, A. Szklo, and R. Schaeffer, "Technical-economic potential of PV systems on Brazilian rooftops," Journal of Renewable Energy, vol. 75, pp. 694-713, 2015.
[25] N. Martín-Chivelet and D. Montero-Gómez, "Optimizing photovoltaic self-consumption in office buildings," Energy and Buildings, vol. 150, pp. 71-80, 2017.

[26] G. Merei, J. Moshövel, D. Magnor, and D. U. Sauer, "Optimization of self-consumption and techno-economic analysis of PVbattery systems in commercial applications," Applied Energy, vol. 168, pp. 171-178, 2016.

[27] T. Lang, E. Gloerfeld, and B. Girod, “Don't just follow the sun - A global assessment of economic performance for residential building photovoltaics," Renewable \& Sustainable Energy Reviews, vol. 42, pp. 932-951, 2015.

[28] M. Castillo-Cagigal, E. Caamaño-Martín, E. Matallanas et al., "PV self-consumption optimization with storage and Active DSM for the residential sector," Solar Energy, vol. 85, no. 9, pp. 2338-2348, 2011.

[29] J. Hoppmann, J. Volland, T. S. Schmidt, and V. H. Hoffmann, "The economic viability of battery storage for residential solar photovoltaic systems - A review and a simulation model," Renewable \& Sustainable Energy Reviews, vol. 39, pp. 1101-1118, 2014.

[30] T. Lang, D. Ammann, and B. Girod, "Profitability in absence of subsidies: A techno-economic analysis of rooftop photovoltaic self-consumption in residential and commercial buildings," Journal of Renewable Energy, vol. 87, pp. 77-87, 2016.

[31] H. Will and F. Zuber, Geschäftsmodelle mit PV Miterstrom, 2016, https://www.pv-mieterstrom.de/wp-content/uploads/2016/11/ PV_Financing_Mieterstrom.pdf.

[32] N.-K. C. Nair and N. Garimella, "Battery energy storage systems: Assessment for small-scale renewable energy integration," Energy and Buildings, vol. 42, no. 11, pp. 2124-2130, 2010.

[33] S. A. Khaparde and A. Mukerjee, "Infrastructure for sustainable renewable energy in India: A case study of solar PV installation," in IEEE Power \& Energy Society General Meeting, pp. 1-7, Piscataway, NJ, USA, 2008.

[34] J. Löfberg, Yalmip, https://yalmip.github.io/, 2016.

[35] Gurobi Optimization, https://www.gurobi.com/, 2016.

[36] Energy Economics Group. Database for Renewable Energy, 2017.

[37] Polarstern, Mieterstrommodell, https://www.polarstern-energie.de/magazin/mieterstrommodell-so-funktioniert-es/, 2017. 

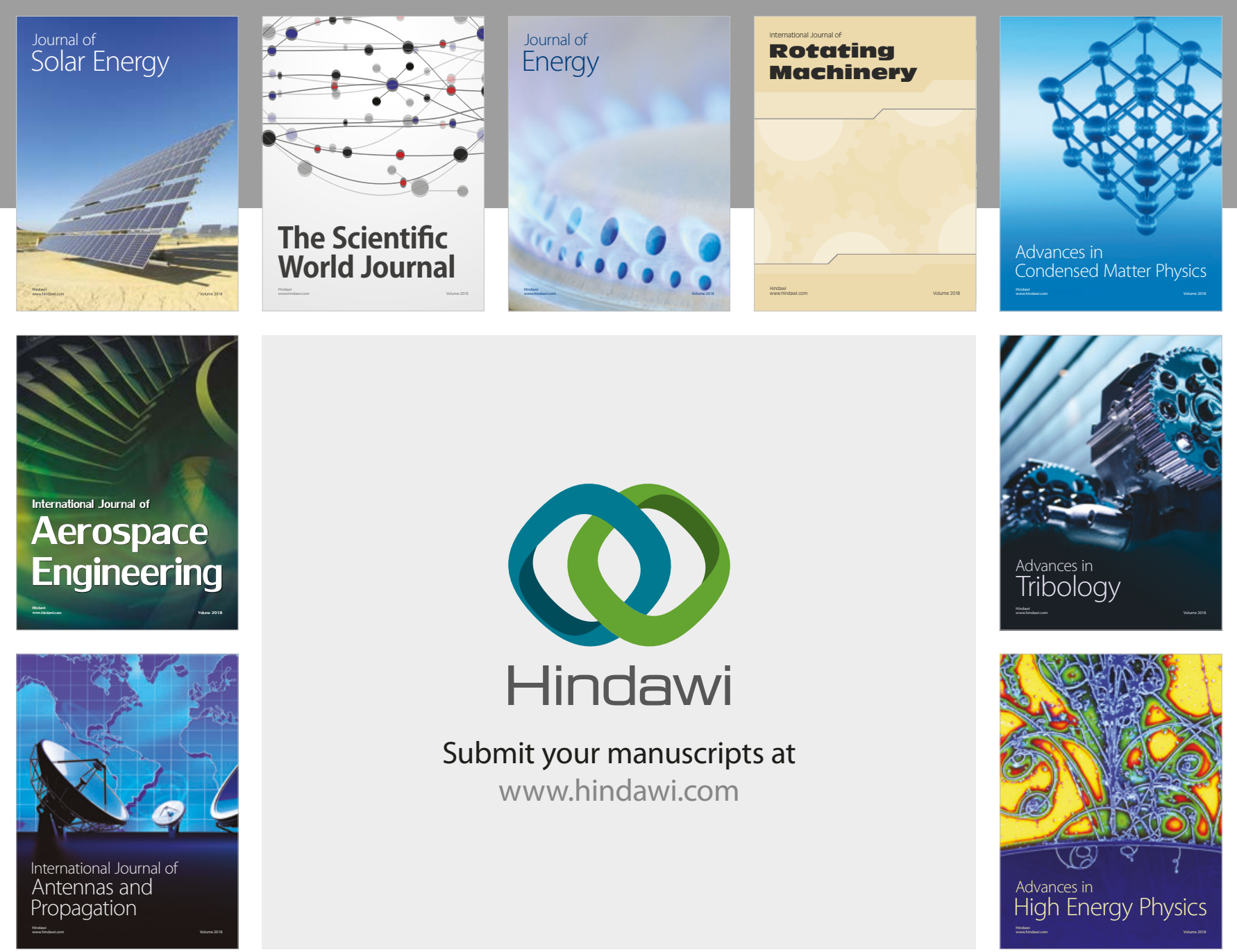

Submit your manuscripts at

www.hindawi.com
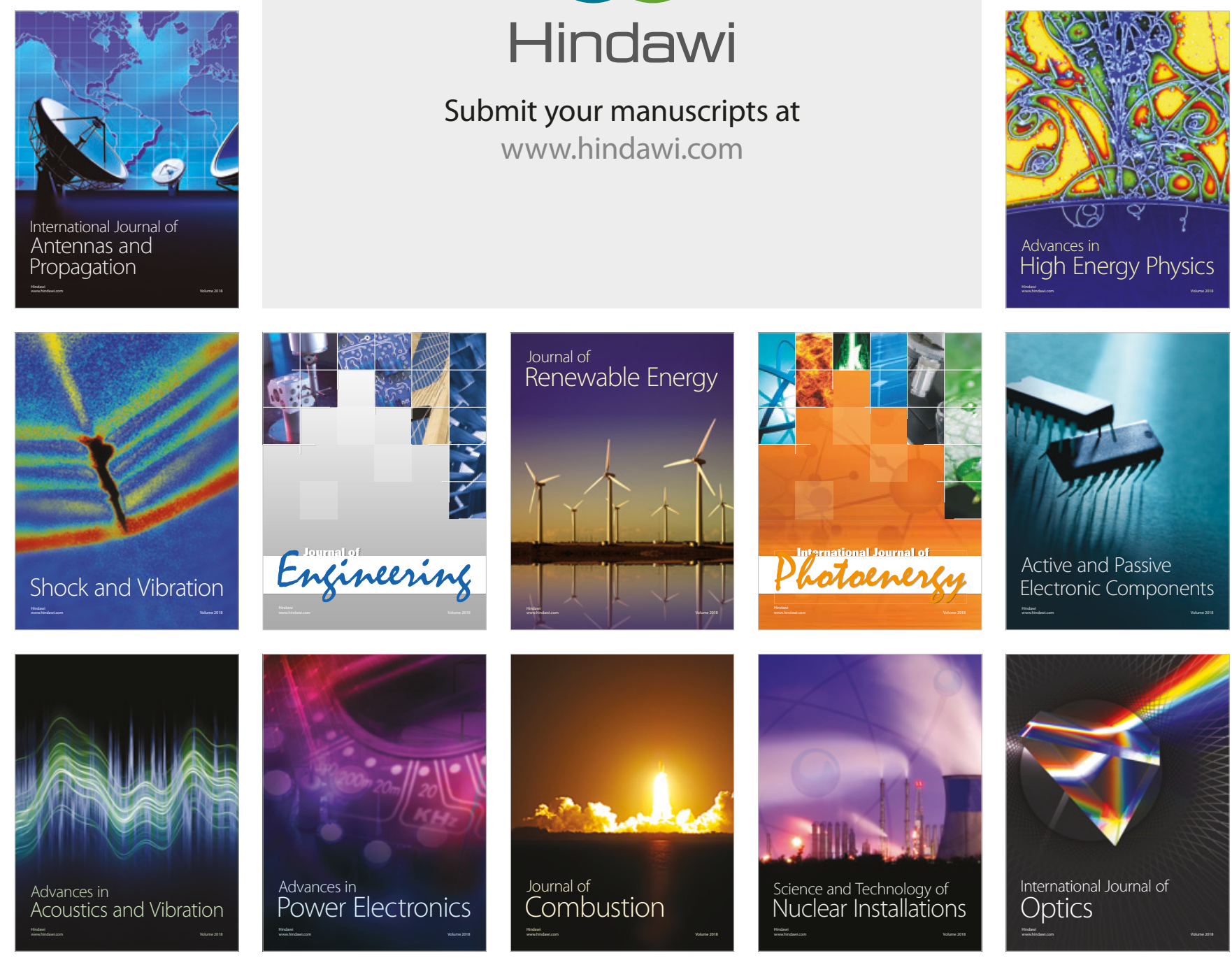